Esta revista forma parte del acervo de la Biblioteca Jurídica Virtual del Instituto de Investigaciones Jurídicas de la UNAM

\title{
EL SOLVE ET REPETE EN EL PANORAMA TRIBUTARIO CUBANO: PRIVILEGIO ADMINISTRATIVO QUE LIMITA EL EJERCICIO DE LOS DERECHOS HUMANOS
}

\author{
THE SOLVE ET REPETE IN THE CUBAN TAX SCENARIO: \\ ADMINISTRATIVE PRIVILEGE WHICH LIMITS \\ THE EXERCISE OF HUMAN RIGHTS
}

\section{Yaneisi BENCOMO FARIÑAS*}

\begin{abstract}
RESUMEN. En el presente trabajo se realiza una valoración del tratamiento técnico-jurídico que se le da a los derechos humanos en la Constitución cubana, reflexionándose en torno a sus aciertos e insuficiencias. De forma paralela se enfatiza en la necesidad de que cada Estado, al instituir las potestades y privilegios de la Administración Pública, garantice que estas no atenten contra el aseguramiento y defensa de los derechos humanos; en tanto estos se constituyen en fin y límites constitucionales del ejercicio del poder estatal.

Asimismo, se realiza un análisis, en la vigente normativa tributaria cubana, a uno de los más reconocidos privilegios administrativos: el solve et repete o pago previo, poniéndose de manifiesto la necesidad de su eliminación ante las consecuencias que su exigencia genera en el ámbito de la protección de los derechos del obligado tributario.
\end{abstract}

Palabras claves: derechos humanos, Constitución, privilegios administrativos (solve et repete).
ABSTRACT: In the present work an assessment is made of the technical and legal treatment given to human rights in the Cuban Constitution, reflecting on its successes and shortcomings. At the same time, it emphasizes the need for each State, by instituting the powers and privileges of the Public Administration, to ensure that these do not infringe on the assurance and defense of human rights; Insofar as these constitute constitutional ends and limits of the exercise of state power.

Likewise, an analysis is carried out, in the current Cuban tax legislation, of one of the most recognized administrative privileges: solve et repete or previous payment, showing the necessity of elimination before the consequences

Key words: human rights, Constitution, administrative privileges (solve et repete).

* Máster en Derecho Constitucional y Administrativo por la Universidad de la Habana, Cuba. 
Esta revista forma parte del acervo de la Biblioteca Jurídica Virtual del Instituto de Investigaciones Jurídicas de la UNAM www.juridicas.unam.mx https://biblio.juridicas.unam.mx/bjv

https://revistas.juridicas.unam.mx

DOI: http://dx.doi_org/10.22201/ijj.24484881e.2017.37.11456

\begin{abstract}
SumARIO: I. Ideas preliminares. II. Derechos humanos. Consideraciones teóricas y expresión en Cuba. III. La exigencia del pago previo en el panorama tributario cubano: un privilegio administrativo permitido y "justificado". IV. La defensa de los derechos humanos. Un imperativo de todos los tiempos. V.

Consideraciones finales. VI. Bibliografía.
\end{abstract}

\title{
I. IDEAS PRELIMINARES
}

El tema de los derechos humanos continúa siendo hoy centro de interés y preocupación de un número cada vez mayor de tratadistas, ${ }^{1}$ sin que exista unanimidad en cuanto a su definición, fundamento y clasificación. Sin embargo, aún cuando hay diversidad de criterios al respecto, existe consenso sobre la necesidad de garantizar su vigencia y protección.

1 Entre los autores que se han dedicado a estudiar el tema se encuentran: Pérez Hernández y Prieto Valdés, "Los derechos fundamentales. Algunas consideraciones doctrinales necesarias para su análisis"; Villabella Armengol, Carlos, "La axiología de los derechos humanos en Cuba" y "Los derechos humanos. Consideraciones teóricas de su legitimación en la Constitución cubana"; Castellanos Ángel M., Cutié Mustelier y Méndez López, "Reflexiones en torno a la protección de los derechos fundamentales en Cuba. Propuesta para su perfeccionamiento" (todas estas obras se encuentran compiladas en Pérez Hernández y Prieto Valdés (comps.), Temas de derecho constitucional cubano, La Habana, Editorial Félix Varela, 2004); Dávalos Fernández, R., Los derechos humanos en la legislación cubana, La Habana, 1989, Colección de Estudios Jurídicos Núm. 7; Fernández Bulté, Julio, "Los fundamentos de los derechos humanos", Seminario sobre Derechos Humanos, San José, CIHD, 1997. También han centrado su atención al análisis de los derechos humanos: Atienza, M., Política y derechos humanos, Valencia, Fernando Torres-Editor, 1976; Peces-Barba, Gregorio, Derechos y deberes fundamentales, Centro de Estudios Constitucionales, 1993; De Castro, Benito, Los derechos económicos, sociales y culturales. análisis a la luz de la teoría general de los derechos humanos, España, Universidad de León, 1993; Robert Alexy, Teoría de los derechos fundamentales, Editorial CEC, 1993; Poval Costa, Ana, "La eficacia de los derechos humanos frente a terceros", Revista de Derecho Político, Madrid, 1991; Cerdas Cruz, Rodolfo, "Democracia y derechos humanos", Estudios básicos de derechos humanos, Editorial CEC, 1995, vol. I; Vasak, K., "La larga lucha por los derechos humanos", El Correo de la UNESCO, 1997. En cuanto a definición se pueden consultar: Peces-Barba, Gregorio, Curso de derechos fundamentales, Universidad Complutense de Madrid, Facultad de Derecho, 1980; Truyol, Antonio, Los derechos humanos, Madrid, Tecnos, 1977. En cuanto a clasificación: Fix-Zamudio, Héctor, La protección procesal de los derechos humanos ante las jurisdicciones nacionales, Madrid, Civitas, 1982. Sobre la naturaleza jurídica de los derechos, Quiroga Cubilla, Derechos y garantías constitucionales en el proceso, Ediciones Librería del Profesional, 1987. 
Esta revista forma parte del acervo de la Biblioteca Jurídica Virtual del Instituto de Investigaciones Jurídicas de la UNAM

Y es que el solo hecho de pertenecer a la raza humana nos otorga una serie de derechos y libertades que deben ser cuidados y respetados por todos y todas; constituyendo un deber de cada Estado la regulación jurídiconormativa, promoción, aseguramiento y defensa de los mismos. Así, el Estado es el principal responsable en adoptar las medidas necesarias para lograr el ejercicio real y efectivo de los derechos humanos por parte de los seres humanos, sin que se instituyan a favor de sus órganos y agentes, potestades, prerrogativas o privilegios cuyo ejercicio mermen o agrieten derechos universalmente reconocidos, como lo son, por ejemplo, el derecho al acceso a la justicia, a la igualdad y no discriminación, a la defensa, la seguridad jurídica, entre otros.

Desafortunadamente, la salvaguarda de algunos derechos humanos no se garantiza plenamente, ya que existen privilegios que en el orden administrativo se le han otorgado a la administración pública y cuyo ejercicio los menoscaban. Estaríamos hablando, por ejemplo, del solve et repete ${ }^{2}$ o pago previo, privilegio que particularmente en la esfera tributaria continúa haciendo nugatorio el ejercicio y defensa de determinados derechos que universalmente han sido consagrados por las normas constitucionales $y$, que en el ámbito internacional, han sido reconocidos también en numerosos tratados internacionales tanto de carácter sectorial, regional como universal.

Precisamente el análisis de este privilegio administrativo en el panorama tributario cubano actual, su incidencia en determinados derechos humanos, así como la defensa y legitimación constitucional de éstos en nuestra carta magna constituyen los ejes temáticos que serán tratados en el presente trabajo.

\section{DERECHOS HUMANOS. CONSIDERACIONES TEÓRICAS Y EXPRESIÓN EN CUBA}

Si sobre derechos dialogamos, lo primero que nos salta a la vista es la multiplicidad de apelativos que a ellos se les han atribuido en la doctrina y en los textos normativos, siendo posible encontrar entre las denominaciones más usadas las de derechos fundamentales y derechos humanos.

El concepto de derechos fundamentales, según nos refiere Nogueira Alcalá, "se reserva generalmente a los derechos de la persona que se en-

2 La locución solve et repete proviene del latín solve, que se deriva de solvendus y significa lo que se debe pagar y repete de la palabra repeto, que significa volver a pedir, repetir, pudiendo ser traducida en castellano como paga y reclama. Ortiz Sánchez, Mónica y Pérez Pino, Virginia, Léxico jurídico para estudiantes, Madrid, Tecnos, 2004, p. 34. 
Esta revista forma parte del acervo de la Biblioteca Jurídica Virtual del Instituto de Investigaciones Jurídicas de la UNAM

cuentran reconocidos por el ordenamiento jurídico de un Estado en la carta fundamental"; 3 de ahí que sean concebidos sólo como tales, al decir de Hernández Valle, “el conjunto de derechos y libertades jurídicas e institucionalmente reconocidos y garantizados por el derecho positivo". 4

Los derechos humanos, por su parte, han sido concebidos desde un sentido conceptual como: "El conjunto de facultades, instituciones y prerrogativas que en cada momento histórico concretan las exigencias de la dignidad, la libertad y la igualdad humana, las cuales deben ser reconocidas positivamente por los ordenamientos jurídicos"; 5 siendo pues "las aspiraciones del hombre, afirmación de fines humanos, demandas del hombre, exigencias éticas del hombre en su vida social que varían en la historia". ${ }^{6}$

Otros autores, como Peces-Barba, prefieren darle una connotación más moral al término derechos humanos, al considerar dentro de él a las aspiraciones humanas que existen, aunque aún no se hayan concretado jurídicamente, puntualizando en tal sentido que: "La acepción incluye también a aquellos supuestos en los cuales esos Derechos Humanos no están incorporados al Derecho positivo". ${ }^{7}$ La noción de derechos humanos se basa en el insoslayable principio del respeto a la dignidad del hombre, estando enfocados precisamente al hombre por el solo hecho de serlo: "Por su propia naturaleza; derechos que le son inherentes y que, lejos de nacer de una concesión de la sociedad política, han de ser por ésta consagrados y garantizados". ${ }^{8}$ En fin: "El hombre es el sujeto de esos derechos en razón o por causa de ser un individuo de la especie humana, y por ello mismo todo hombre y cada hombre los titulariza". 9

Aún cuando para algunos esta distinción semántica pueda resultar trivial, de los criterios expuestos supra se desprende una conclusión: admitir como fundamentales — en función de su mayor eficacia y protección- a unos

3 Nogueira Alcalá, Humberto, Teoría y dogmática de los derechos fundamentales, México, UNAM, Instituto de Investigaciones Jurídicas, 2003, p. 58.

4 Hernández Valle, Rubén, La tutela de los derechos fundamentales, San José, Costa Rica, 1990, p. 13.

5 Pérez Luño, Antonio, Los derechos fundamentales, Madrid, Tecnos, 1994, p. 44.

6 Conde Álvarez, Enrique, El régimen político español, Madrid, Tecnos, 1994, p. 339.

7 Peces-Barba, Gregorio, Derechos y deberes fundamentales, Madrid, Centro de Estudios Constitucionales, 1993, p. 323.

8 Truyol y Serra, Antonio, Los derechos humanos, Madrid, Civitas, 1968, p. 11.

9 Bidart Campos, Germán J., Teoría general de los derechos humanos, México, UNAM, Instituto de Investigaciones Jurídicas, 1989, pp. 13 y 14. 
Esta revista forma parte del acervo de la Biblioteca Jurídica Virtual del Instituto de Investigaciones Jurídicas de la UNAM

derechos y a otros no, entraña inevitablemente una jerarquización jurídica $\mathrm{y}$, por ello, se crea dentro del conjunto de derechos un área jerarquizada por su contenido, importancia, e inmediatez, los que serán protegidos de forma más eficaz mediante vías expeditas de tutela judicial. De tal modo, la protección y tutela ofrecida por los ordenamientos constitucionales a los derechos depende precisamente del término que los cualifique; estando ceñido el ámbito protector de la vía judicial sólo a los concebidos como fundamentales.

Para nada compartimos esta distinción, pues consideramos que, tal y como ha defendido Cutié Mustelier, lo viable y justo es designar a todos los derechos como humanos, para así: "Defender la postura de que todos los derechos son iguales, interdependientes e indivisibles y por tanto imprescriptibles para la vida humana", ${ }^{10}$ y de esta forma podamos situarlos al mismo nivel y dotarlos de iguales garantías y ofrecerles la misma protección. Bajo esta rúbrica quedarían entonces englobados tanto los derechos civiles y políticos como los económicos, sociales y culturales, e incluso los de la tercera generación, debiéndose tener presente varias premisas si a la realización y protección de tales derechos se aspira. Entre estas premisas podemos señalar las siguientes: su reconocimiento en los textos constitucionales, la creación de las condiciones materiales que permitan su viabilidad, la inclusión de un amplio sistema de garantías que los tutelen de forma eficaz, así como la necesaria cultura constitucional que deben poseer todos los dirigentes y funcionarios estatales y administrativos, así como otros entes sociales y privados: la población en general.

En los últimos años, la consagración de los derechos humanos en los ordenamientos constitucionales latinoamericanos se ha desarrollado de manera considerable, siendo incluso enriquecidos, tal y como nos indica Fix-Zamudio: "Con los establecidos en los instrumentos internacionales ratificados por los gobiernos latinoamericanos, y que constituyen el derecho internacional de los derechos humanos, estos últimos considerados como de naturaleza progresiva". ${ }^{11}$

10 Cutié Mustelier, Danelia, El sistema de garantías de los derechos humanos en Cuba, tesis doctoral inédita, Cuba, 2001, p. 33.

11 Fix-Zamudio, Héctor, Los derechos humanos y su protección juridica y procesal en Latinoamérica, México, UNAM, Instituto de Investigaciones Jurídicas, 1974, p. 15. Entiende este autor que si bien los derechos humanos son reconocidos en los ordenamientos constitucionales latinoamericanos, se advierte la necesidad de vigorizar la protección jurídica y procesal de éstos, por conducto de los instrumentos tanto de carácter tradicional 
Esta revista forma parte del acervo de la Biblioteca Jurídica Virtual del Instituto de Investigaciones Jurídicas de la UNAM

En Cuba, desde el mismo triunfo de la Revolución el 1o. de enero de 1959, el Estado ha sido garante y protector de los derechos humanos y libertades individuales, haciendo suyos los valores humanistas contenidos en la Declaración Universal de los Derechos Humanos del 10 de diciembre de 1948.

La Constitución Cubana de 1976 — seguidora del modelo constitucional socialista de tipo estatalista derivado de la experiencia del constitucionalismo soviético - abarca en su cuerpo un amplio conjunto de derechos y libertades de los ciudadanos, comprendiendo no sólo los derechos de la primera generación, sino además los de la segunda y tercera. Así, agrupados en el capítulo VII bajo la denominación "Derechos, deberes y garantías fundamentales", ${ }^{12}$ aparecen regulados en nuestra Ley Primera, el núcleo principal de derechos reconocidos, a saber: derecho al trabajo (y vinculados a éste, el derecho al descanso, a la seguridad social y a la protección e higiene del trabajo); a la asistencia social (para los incapacitados o sin amparo); derecho a la atención médica y estomatológica; a la educación; al deporte, la educación física y la recreación; a la libertad de palabra y prensa (conforme a los fines de la sociedad socialista); derechos de reunión, manifestación y asociación; a la inviolabilidad de la persona, el domicilio y la correspondencia; libertad de conciencia y culto religioso;

como de los más novedosos. En esta materia, el derecho constitucional latinoamericano ha sido muy imaginativo, ya que ha creado varios instrumentos específicos para otorgar mayor dinamismo a ciertos derechos humanos que han asumido particular significado en los años recientes, entre ellos los de carácter colectivo, incluyendo los considerados como transpersonales o difusos; el derecho de información y los correlativos de la protección de la intimidad, la honra y la dignidad de las personas; la introducción de organismos no jurisdiccionales para la tutela rápida y eficaz de los particulares frente a los actos y resoluciones administrativas, entre otros.

12 La denominación derechos fundamentales empleada en la Constitución no coincide con la otorgada en la doctrina española y alemana, no supone en las actuales condiciones, garantía judicial reforzada ni la existencia de un procedimiento especial para su defensa. Por tal motivo, teóricamente es discutible y deficiente, de ella se pudiera colegir que se discrimina a un segundo plano los derechos enunciados fuera de este capítulo, lo que ciertamente es injustificado cuando se constata que efectivamente no fue objetivo del legislador constituyentista crear un área prioritaria de derechos y reconocer unos como fundamentales y otros como no, pues de la lectura del artículo 137 se evidencia la equiparación de todos los derechos contenidos en la carta magna, al dotarlos a todos de la garantía legislativa allí contenida, a saber, el reconocimiento de los derechos como contenidos especialmente protegidos ante la reforma constitucional. Villabella Armengol, Carlos M., "Los derechos humanos. Consideraciones teóricas de su legitimación en la Constitución Cubana", en Pérez Hernández y Prieto Valdés (comps.), Temas de derecho constitucional cubano, La Habana, Editorial Félix Varela, 2004, p. 320. 
Esta revista forma parte del acervo de la Biblioteca Jurídica Virtual del Instituto de Investigaciones Jurídicas de la UNAM

entre otros. ${ }^{13}$ Todos requieren de la acción estatal para su ejercicio, su disfrute depende del condicionamiento material proveniente del régimen.

Sin embargo, no es únicamente en este capítulo en el que se encuentran regulados los derechos, sino que, como consecuencia de la deficiente técnica empleada en cuanto a su agrupación en el texto constitucional, podemos encontrar fuera de éste otros derechos dispersos de igual significación, tales como el derecho a la ciudadanía, ${ }^{14}$ al matrimonio, ${ }^{15}$ a la libertad de creación artística, científica e intelectual, ${ }^{16}$ a la investigación, ${ }^{17}$ al sufragio, ${ }^{18}$ a participar en la vida política del país, ${ }^{19}$ a la herencia,${ }^{20}$ el derecho a reclamar y a recibir la reparación correspondiente ante la actuación indebida de un funcionario estatal, ambos en el capítulo de los fundamentos económicos del Estado.

Por otro lado, se advierte que existen otros derechos que han quedado fuera de nuestra carta magna, siendo algunos consagrados en la legislación ordinaria. Tal es el caso del derecho a la presunción de inocencia; práctica que implica entender esas normas como una extensión de la Constitución en materia de derechos humanos.

A las dificultades ya referidas se añade la inadecuada arquitectura semántica seguida en algunos casos, lo que provoca que en determinadas instituciones sea un tanto difícil apreciar si se configura un derecho o si simplemente lo que existe es una especial protección del Estado.

Sobre la base de los razonamientos realizados a priori, se puede constatar que ha sido defectuosa la técnica empleada en cuanto a la agrupación de los derechos, hecho que ha provocado una dispersión de los mismos en el texto constitucional. Además, utilizar la denominación de fundamentales implica discriminar los derechos enunciados fuera del capítulo VII, expresión que por demás resulta injustificada cuando se comprueba la falta de intención en crear un área prioritaria de derechos. Es importante tener en cuenta con relación al tema que nos ocupa que aun cuando en la letra de la norma constitucional cubana existe un capítulo para los derechos constitucionales, y hay otros derechos fuera, la protección del procedimiento

\footnotetext{
13 Constitución de la República de Cuba de 1976, artículos 45-66.

14 Ibidem, artículo 32.

15 Ibidem, artículo 36.

16 Ibidem, artículo 39, incisos ch y f.

17 Ibidem, artículo 39, inciso e.

18 Ibidem, artículo 132.

19 Ibidem, artículo 131.

20 Ibidem, artículo 24.
} 
Esta revista forma parte del acervo de la Biblioteca Jurídica Virtual del Instituto de Investigaciones Jurídicas de la UNAM

especial de reforma ${ }^{21}$ es para todos los derechos que se encuentran regulados en la Constitución.

Pero no son sólo insuficiencias las que se encuentran presentes en nuestra carta magna, sino que también se evidencian aciertos, como lo es el hecho de consagrarse en el propio articulado un conjunto de condicionantes materiales que hacen tangible en la práctica cada uno de los derechos en ella regulados.

De forma general, como características de la regulación constitucional de los derechos en Cuba podemos significar que $:^{22}$

- No siempre aparecen formulados de forma directa, sino que a veces están como garantías materiales o jurídicas de los mismos.

- A pesar de existir un capítulo para los derechos fundamentales, existen otros también fundamentales que están dispersos en el texto.

- No se conciben los derechos como facultades absolutas de su titular, sino que se les reconoce ciertos límites desde su configuración como derecho, para garantizar la salvaguarda de los derechos y libertades de los demás y del orden imperante. Por tanto, se reconocen con límites a su ejercicio, establecidos constitucionalmente y por la normativa ordinaria.

21 La reforma constitucional es lo que permite adecuar el texto constitucional a los cambios sociales producidos o necesarios, por lo que ella ofrece la posibilidad de continuidad y de legitimidad, pero por sí sola no es garantía de estabilidad, sino que se requiere del procedimiento especial para la supresión, modificación o adición de contenidos, diferente del necesario para modificar o derogar las leyes ordinarias. Si el texto constitucional entró en vigor mediante referendo popular, la subrogación de un texto por otro, también requiere la aprobación del pueblo mediante referendo convocado a tal afecto. En el caso de Cuba, la participación directa de los ciudadanos en la toma de decisiones mediante su voto es determinante, como manifestación de su poder constituyente y de la titularidad que ostenta de la soberanía. La Constitución cubana puede ser reformada de manera total y parcial, estableciéndose en el texto dos procedimientos diferentes para su modificación: voto nominal de una mayoría no inferior a las dos terceras partes de los integrantes de la ANPP, para modificar parte del texto; además del voto anterior, voto popular mayoritario en referendo convocado al efecto, para la subrogación de un texto por otro. Existen además contenidos especialmente protegidos, por cuanto la Constitución establece, que si la modificación trata de derechos y deberes consagrados en la Constitución, o de la integración y atribuciones de la Asamblea Nacional del Poder Popular o del Consejo de Estado, se requiere además del voto nominal, el voto mayoritario en referendo popular.

22 Prieto Valdés, Marta, Guía de derecho constitucional cubano (material digital), Universidad de La Habana, Departamento de Estudios Jurídicos Básicos, p. 25. 
Esta revista forma parte del acervo de la Biblioteca Jurídica Virtual del Instituto de Investigaciones Jurídicas de la UNAM

- Los derechos socioeconómicos y culturales aparecen en un primer plano, resultado de la concepción prevaleciente de su primacía para la existencia del hombre en el momento histórico de adopción del texto. En ocasiones estos derechos se consideran además como deberes, a partir de las garantías que reciben y de la importancia que se les concede.

- No son ejercitables, como derechos constitucionales, frente al Estado.

- La interpretación del contenido de los derechos tutelados constitucionalmente se ejerce en la práctica por los órganos superiores del poder popular y no por la administración judicial.

- Se consideraron como contenidos especialmente protegidos ante las reformas parciales de la Constitución.

Ciertamente, los derechos humanos constituyen un tema espinoso técnica y políticamente, siendo acuciante e impostergable el reconocimiento íntegro de todos ellos en los textos constitucionales de todos los países del mundo, careciendo de validez cualquier jerarquización jurídica que entre ellos se haga.

A la par constituye un deber de cada Estado el reconocimiento y aseguramiento constitucional de todos los derechos humanos en su totalidad. No debemos olvidar que estos derechos comprenden las aspiraciones y exigencias de la dignidad humana en cada momento histórico, de ahí que sea un imperativo cada vez mayor el establecimiento de garantías que permitan asegurar su eficacia práctica a través de la instrumentación de mecanismos protectores diversos, que pueden ir desde los tradicionales medios jurisdiccionales hasta las vías extrajudiciales y las llamadas garantías normativas; sin que para ello resulte preciso distinguir si son fundamentales o no los derechos, pues todos ellos merecen igual tutela y protección.

Lo que se ha querido plantear es que si bien la tutela constitucional constituye la primera garantía jurídica de los derechos humanos, debemos recordar que no es la única. En la sociedad, el individuo establece una relación básica con el Estado, y de ésta derivan derechos y deberes para ambas partes de la relación. Lo antes expuesto supone la obligación del Estado, al reconocer los derechos conforme a las posibilidades del régimen, de ofrecer las garantías que propicien el disfrute de los mismos, y el derecho del Estado a exigir el respeto al orden jurídico-político, incluyendo los derechos de terceras personas. Implica además el derecho del individuo de satisfacer sus necesidades y 
Esta revista forma parte del acervo de la Biblioteca Jurídica Virtual del Instituto de Investigaciones Jurídicas de la UNAM

realizar sus aspiraciones básicas mediante el ejercicio de sus derechos, y el deber de los individuos de cumplir con la normativa adoptada por el Estado y de respetar los derechos de los demás. La igualdad es elemento esencial, entonces, para la realización del derecho, la salvaguarda de la legalidad y la seguridad jurídica ciudadana. Por tanto, no se conciben hombre y Estado enfrentado, sino en estrecha relación, a partir del reconocimiento del derecho de la mayoría a participar en la vida sociopolítica y en la determinación de los destinos del país, en igualdad de condiciones. Si añadimos las características del Estado cubano y del sistema político imperante, al hecho de que no se establecen límites a la actuación del Estado, y que los derechos no son ejercitables contra la administración, sino que ésta tiene la función de garantizarlos, se puede comprender que se tutelaron constitucionalmente los derechos con el objetivo de reconocer cuáles habían sido los derechos conquistados y garantizados, básicamente por el proceso revolucionario, y de otros que son necesarios para la existencia y desarrollo de la personalidad humana, a partir de la noción de que los derechos son regulados desde la mayoría y destinados al disfrute de ésta.

No obstante, no siempre todos los derechos son garantizados ni tampoco esta igualdad se manifiesta en todas las aristas del funcionamiento del aparato estatal, $y$, en particular, en el ámbito administrativo.

A modo de ejemplo se encuentra el desenvolvimiento del procedimiento de gestión de los tributos, ${ }^{23}$ en el que se generan una serie de vínculos y relaciones jurídicas de diversos alcances y contenidos para los sujetos implicados. En Cuba encontramos, de una parte, a la administración tributaria (ONAT) como representante del Estado, ocupando una posición preponderante al fungir como acreedora dentro de la relación obligacional tributaria, investida a tales efectos de potestades conferidas por ley. ${ }^{24} \mathrm{De}$

23 El procedimiento de gestión constituye un mecanismo procedimental a través del cual la administración pública percibe la prestación debida por el sujeto pasivo o responsable en calidad de tributo. Está compuesto esencialmente por tres actividades: la gestión propiamente dicha, la recaudación o cobranza y la fiscalización. Reyes Rodríguez, Raudel, "Procedimiento en materia fiscal (I). Procedimiento de gestión y cobranza de los tributos", en Colectivo de autores, Apuntes de derecho financiero cubano, La Habana, Editorial Félix Varela, 2007, pp. 186 y 187.

24 En tal sentido, la vigente Ley Núm. 113 Del Sistema Tributario, del 23 de julio de 2012 (publicada en Gaceta Oficial Ordinaria Núm. 53 del 21 de noviembre de 2012), establece que: "La Oficina Nacional de Administración Tributaria, la Aduana General de la República y otras entidades que se autoricen a ejercer funciones de Administración Tributaria, gestionan, controlan, recaudan, determinan y fiscalizan los tributos, incluyendo 
Esta revista forma parte del acervo de la Biblioteca Jurídica Virtual del Instituto de Investigaciones Jurídicas de la UNAM www.juridicas.unam.mx https://biblio.juridicas.unam.mx/bjv

https://revistas.juridicas.unam.mx

DOI: http://dx.doi.org/10.22201/ijj.24484881e.2017.37.11456

EL SOLVE ET REPETE EN EL PANORAMA TRIBUTARIO CUBANO...

otro lado tenemos al contribuyente, deudor por deuda propia, a quien la ley impone la carga tributaria en tanto es el realizador del hecho imponible, configurándose así como el verdadero sujeto pasivo: "Titular de la obligación tributaria principal y de los deberes que tal hecho jurídico comporta". ${ }^{25}$

Ciertamente no se encuentran el contribuyente y la administración tributaria en un plano de igualdad, pues esta última cuenta con un conjunto de potestades y facultades que le garantizan el cobro final del tributo, mientras que al contribuyente no le resta más que esperar a que la ONAT —en ejercicio de sus facultades y dentro del marco de su competencia- dicte cuantas resoluciones, providencias o requerimientos sean necesarios, para poder entonces instar a ella y reclamar aquellas decisiones que considere injustas, incorrectas o no conformes a derecho, configurándose así la posibilidad de revisión del acto administrativo-tributario.

En nuestro sistema tributario esta revisión se realiza en primera instancia en vía administrativa, etapa donde es la propia administración tributaria, como juez y parte, quien decide sobre la legalidad de sus propios actos al dar respuesta a los recursos que pueden ser interpuestos, a saber, recursos de reforma y alzada, ${ }^{26}$ exigiéndose como requisito indispensable para la presentación de este último, el previo ingreso en calidad de depósito de la cantidad adeudada por el recurrente o a él reclamada, poniéndose así de manifiesto el solve

los intereses, la aplicación de los recargos y sanciones que en su caso correspondan, las solicitudes de devoluciones de ingresos y la solución de las reclamaciones que se presenten contra sus actos; para lo cual podrán dictar cuantas resoluciones, providencias o requerimientos sean necesarios, en el marco de su competencia”. Cfr. artículo 388 de la Ley Núm. 113/12. Asimismo, el Decreto Núm. 308 Reglamento de las Normas Generales y de los Procedimientos Tributarios, del 31 de octubre de 2012 (publicado en Gaceta Oficial Ordinaria Núm. 53 de 21 de noviembre de 2012) delinea las funciones que la ONAT está llamada a realizar entre las que se pueden citar: "El control sistemático que sobre el pago de la deuda tributaria esta efectúa; la determinación administrativa de la deuda tributaria cuando corresponda; el cobro forzoso de la deuda tributaria — procediendo al embargo de bienes de la propiedad del contribuyente-; la imposición de los recargos y sanciones que procedan por el incumplimiento de las obligaciones tributarias; la resolución de los recursos que se interpongan contra sus actos administrativos"; entre otras, $c f r$. artículos 12 y 13 del Decreto Núm. 308/12.

25 Calvo Ortega, Rafael, Curso de derecho financiero I. Derecho tributario, parte general, Barcelona, Civitas, 2008, p. 167. El pago de los tributos como obligación principal a cumplir por parte de todo sujeto pasivo, así como los deberes formales que está llamado también a efectuar, se encuentran regulados en los artículos 391 y 393 de la Ley Núm. $113 / 12$.

26 Estos recursos se encuentran regulados en el título II, artículos 464-473 de la Ley Núm. 113/12, así como en los artículos 183-201 del Decreto Núm. 308/12. 
Esta revista forma parte del acervo de la Biblioteca Jurídica Virtual del Instituto de Investigaciones Jurídicas de la UNAM

et repete. Únicamente agotada la vía administrativa es que el contribuyente puede entonces optar por la vía judicial.

El solve et repete se convierte así en un requisito sine qua non para admitir la tramitación de la impugnación de los actos administrativos-tributarios en vía administrativa - en caso de inconformidad con la respuesta dada en reforma - y por ello, en la jurisdiccional. La exigencia de este pago previo deja así al obligado tributario en un verdadero estado de indefensión en el caso de no contar con los recursos monetarios para hacer frente al depósito de la cantidad reclamada por la ONAT.

Tal situación se erige en un desafío que se abre paso cada día con mayor fuerza: lograr una mayor protección de los derechos del sujeto pasivo en la relación jurídico-tributaria, en aras de conferirle seguridad jurídica frente a los actos desarrollados por la administración pública en la esfera fiscal.

\section{LA EXIGENCIA DEL PAGO PREVIO EN EL PANORAMA TRIBUTARIO CUBANO: UN PRIVILEGIO ADMINISTRATIVO PERMITIDO Y "JUSTIFICADO"}

La relación jurídico-tributaria se manifiesta, en la mayoría de las ocasiones, como una relación conflictual y desproporcionada en la que la administración cuenta con privilegios a los efectos de proteger la correcta y rápida percepción del crédito fiscal. Además del interés general que media como justificación para la exigencia de tales prerrogativas, se invocan como fundamentos la presunción de legitimidad de la pretensión estatal, así como la ejecutividad y ejecutoriedad de los actos administrativos. Sin embargo, se nos puede presentar el problema de que tales ventajas, como ocurre con la exigencia del pago previo, puedan llegar a afectar derechos humanos.

Adentrarnos en el análisis del solve et repete implica irrumpir en temas tan sensibles como la protección jurídica del sujeto pasivo frente a los actos de la administración tributaria, $y$, consecuentemente, el necesario control de tales actos sin trabas u obstáculos, mucho menos de índole económica, que limitan su consecución plena y socavan los cimientos mismos de la justicia administrativa, ${ }^{27}$ particularmente la tributaria.

27 Tal y como sostiene el destacado jurista mexicano Fix-Zamudio: "La justicia administrativa comprende un conjunto bastante amplio y crecientemente complejo de instrumentos jurídicos y procesales para la tutela de los derechos subjetivos y los intereses 
Esta revista forma parte del acervo de la Biblioteca Jurídica Virtual del Instituto de Investigaciones Jurídicas de la UNAM

Concebida la justicia administrativa como género en el cual queda comprendida la jurisdicción para la solución de los conflictos que se suscitan entre la administración pública y los particulares, se ha erigido desde los últimos tiempos la jurisdicción contencioso-administrativa: "Vía por excelencia para lograr la mejor fiscalización de la actividad administrativa al reunir mayores garantías jurídicas", ${ }^{28}$ al ser precisamente en sede judicial donde los sujetos en conflicto encuentran, en primer lugar, la necesaria imparcialidad. Sin embargo, aún cuando el control jurisdiccional de los actos de la administración pública constituye, como indica Jinesta Lobo, "un medio para mantener el Estado Social de Derecho, al garantizarle al particular una serie de derechos y prestaciones, y de otra parte, combatir las arbitrariedades y abusos de la Administración en su rol intervencionista", ${ }^{29}$ se continúa haciendo engañoso tal control a través de la creación de categorías de actos excluidos y el establecimiento de una serie de obstáculos para acceder a la tutela jurisdiccional, como es el caso del solve et repete. Este requerimiento de tipo económico implica "un condicionamiento de la admisibilidad de los reclamos administrativos o las acciones contencioso-administrativas en contra de multas u otras obligaciones dinerarias declaradas a favor de la Administración, al pago previo de ésta, por parte del particular afectado". ${ }^{30}$

El análisis de este privilegio administrativo constituye un tema que cobra especial relevancia e interés en Cuba, toda vez que su análisis nos adentra en el ámbito de la protección jurídica del contribuyente frente a los actos de la administración tributaria. En la actualidad, nos encontramos inmersos en un conjunto de transformaciones en el orden económico, dentro de las que sobresale el fortalecimiento del sistema impositivo

legítimos de los particulares frente a la actividad de la Administración Pública, por medio de los cuales se resuelven las controversias que se producen entre la Administración y los particulares." Fix-Zamudio, Héctor, "Concepto y contenido de la justicia administrativa", en Cisneros Farías et al. (coords.), Justicia administrativa. Segundo Congreso Iberoamericano de Derecho Administrativo, México, UNAM, Instituto de Investigaciones Jurídicas, 2007, p. 178.

28 Martín Rebollo, Luis, "La justicia administrativa ante el texto constitucional", Revista Española de Derecho Administrativo, España, Núm. 19, octubre-diciembre de 1978, p. 529.

29 Jinesta Lobo, Ernesto, "El control jurisdiccional de la administración pública", Revista Judicial, año XX, núm. 63, Costa Rica, septiembre de 1997, p. 106.

30 Ferrada Bórquez, Juan C., "Las potestades y privilegios de la administración pública en el régimen administrativo chileno", Revista de Derecho, Chile, vol. XX, núm. 2, 2007, p. 84. 
Esta revista forma parte del acervo de la Biblioteca Jurídica Virtual del Instituto de Investigaciones Jurídicas de la UNAM

cubano; donde cada vez son más los sujetos tributarios a proteger, lo que inevitablemente implica continuar perfeccionando nuestro sistema tributario, de ahí que éste sea el marco ideal para tratar este tema por la utilidad que en la práctica nos reporta.

En el panorama tributario cubano se permite la exigencia de este privilegio procedimental en virtud de la vigente Ley Núm. 113 del Sistema Tributario y el Decreto Núm. 308, Reglamento de las Normas Generales y de los Procedimientos Tributarios, ambas normativas jurídicas que fueron debatidas y aprobadas durante el IX Periodo Ordinario de Sesiones de la Asamblea Nacional del Poder Popular y finalmente publicadas el 21 de noviembre del propio año en la Gaceta Oficial de la República de Cuba, para entrar en vigor el 1 de enero de 2013.

Regulada en el título segundo del libro sexto de la Ley Núm. 113/12, así como en el capítulo XI de su reglamento, bajo la denominación "De los recursos", aparece reglamentada en estas normas jurídicas la exigencia del procedimiento de impugnación anterior a la habilitación de la instancia judicial —es decir, el agotamiento de la vía administrativa previa — ${ }^{31} \mathrm{y}$, con él, el requerimiento del solve et repete. A partir del artículo 464 y hasta el 473 (ambos inclusive) de la Ley Tributaria, así como del 183 y hasta el 201 del Decreto Núm. 308/12, se conforma esta vía a partir de dos recursos fundamentales: reforma y alzada, debiendo quedar resuelto el primero para poder interponer el segundo.

A tono con la tradición que en materia procedimental se tenía en nuestro país, el solve et repete es exigible durante la vía gubernativa sólo al momento de interponer el recurso de alzada, constando así en los artículos 467 y 193 de la Ley Tributaria y su reglamento, respectivamente, los que taxativamente refieren lo siguiente: "El Recurso de Alzada procede contra toda resolución que desestime en todo o en parte el Recurso de Reforma, previo ingreso de la cantidad reclamada en calidad de depósito o cumplimentando la garantía exigida".

31 La exigencia de la satisfacción de la vía administrativa previa como requerimiento para que tenga lugar la revisión judicial de los actos de la administración tributaria está presente en la norma cubana de trámites (LPCALE), cuando se establece que: "El proceso contencioso-administrativo procede contra las resoluciones que no sean susceptibles de ulterior recurso en la vía administrativa, ya sean definitivas o de trámite, siempre que decidan directa o indirectamente el fondo del asunto, de forma tal que sea imposible continuar con el mismo". Artículo 670 de la LPCALE. Así lo ratificó el Dictamen Núm. 61 del 30 de abril de 1978, del Consejo de Gobierno del Tribunal Supremo Popular. 
Esta revista forma parte del acervo de la Biblioteca Jurídica Virtual del Instituto de Investigaciones Jurídicas de la UNAM

De su regulación en estas normas se desprenden los rasgos que caracterizan a este privilegio administrativo en nuestro ordenamiento jurídicotributario, a saber:

- Se exige durante la vía administrativa previa.

- La negación de su doble pedido, toda vez que el solve et repete sólo es requerido para la interposición del recurso de alzada. ${ }^{32}$

- Resulta ser una especie de simbiosis de las tesis administrativista y procesalista, al fundamentarse en la ejecutoriedad del acto administrativo objeto de litis, así como en la necesaria condición de pago para que sea conocido en el recurso de alzada, en sede administrativa interna, y luego, en proceso contencioso.

- La cantidad abonada por el contribuyente deudor (o su representante legal) se aporta en calidad de depósito. ${ }^{33}$

- El no cumplimiento trae consigo la declaración de inadmisibilidad del recurso de alzada, quedando cerradas las puertas para poder interponer demanda administrativa en la vía judicial. ${ }^{34}$

- A solicitud del reclamante y teniendo en cuenta su liquidez y otras circunstancias que dieron lugar a la determinación de la deuda tributaria, el no cumplimiento del requisito del pago previo puede ser declarado con carácter excepcional para la tramitación del recurso de alzada por la autoridad que conoce este recurso. ${ }^{35}$

32 Para interponer recurso de reforma no se exige el solve et repete, y así lo ha dejado consignado el artículo 465 de la Ley Núm. 113/12.

33 Aunque en el propio artículo ni en ningún otro precepto de estas normas se hace otra referencia al citado depósito, ni a cuáles serán las garantías, de constituirse, para el obligado tributario y para la Administración, del cumplimiento o eficacia del depósito, lo que indudablemente afecta la seguridad de la obligación. Pérez Urquiza, Yalenni, La solución de los conflictos tributarios en la vía judicial en Cuba, tesis presentada en opción al título académico de doctor en ciencias, inédita, Cuba, 2011, p. 121.

34 Ley Núm. 113/12 y Decreto Núm. 308/12, artículos 470 y 197, respectivamente.

35 Es este un elemento novedoso en nuestra práctica fiscal, introducido por el artículo 194 del Decreto Núm. 308/12 y sobre el que la Ley Núm. 113/12 es totalmente omisa. Sin duda, constituye un progreso en lo que a la protección jurídica del contribuyente se refiere. Sin embargo, si bien su inclusión abre la posibilidad para el sujeto pasivo de poder recurrir en alzada sin tener que para ello pagar previamente el monto que a él se le exige, su regulación se limita al análisis e investigación de la liquidez del contribuyente que lo solicita, así como de las circunstancias que motivaron la determinación de la deuda tributaria, quedando sujeta de esta forma la declaración de excepcionalidad a 
Esta revista forma parte del acervo de la Biblioteca Jurídica Virtual del Instituto de Investigaciones Jurídicas de la UNAM

Por otra parte, la "justificación" que se le ha dado al pago previo para mantener su presencia en la letra de las normas jurídicas, así como en la práctica fiscal es de orden práctico: lograr la recaudación de los ingresos tributarios de forma puntual, amparándose para ello en la presunción de legitimidad y en el principio de ejecutoriedad que caracterizan a los actos administrativos, y que de forma similar trascienden a la esfera tributaria. Sin embargo, se ha podido demostrar que tal justificación resulta insatisfactoria, no debiendo el Estado hacer uso de este privilegio con el pretexto de la necesidad de evitar que los contribuyentes, al impugnar los actos administrativos-tributarios por medio de la interposición de los recursos conferidos por la ley, obstaculicen la normal y regular percepción de la renta pública. Ciertamente, el Estado no puede paralizar el procedimiento de gestión de los tributos, pues de ello depende en gran medida que cumpla con sus fines, que son básicamente: la educación, la salud, la seguridad de toda la población, etcétera. Pero es también cierto que con la exigencia del pago previo se está ejerciendo sobre el deudor tributario una presión para constreñirle, también por esta vía, a cumplir en tiempo oportuno la obligación pecuniaria resultante del proceso de liquidación, mas no puede ser considerado este pago como parte de las arcas fiscales hasta tanto no se resuelva la controversia, la que debe ser a favor del Fisco para que efectivamente pueda éste disponer de la suma previamente depositada por el contribuyente.

Ténganse en cuenta, igualmente, que la posibilidad de revisión judicial del acto de determinación tributaria sin exigirse el pago previo de la prestación, no subvierte la presunción de legitimidad del acto administrativo ni inhibe su fuerza ejecutoria. Recordemos que una de las principales consecuencias que se desprende de la ejecutoriedad del acto administrativo es que el acto debe por principio ejecutarse a pesar de la interposición de recursos contra él; es decir, que la interposición de recursos contra el acto no suspende su ejecución, de ahí que la exigencia del pago previo no tendría razón de ser si lo que se quiere es evitar que se suspenda la ejecución de los dictaminado por la administración tributaria, puesto que la mera interposición de una reclamación no es óbice para que el acto administrativo-tributario deje de desplegar sus efectos.

la valoración que en ejercicio de esta facultad discrecional haga la autoridad competente de la administración tributaria inmediata superior de la que resolvió el recurso de reforma. 
Esta revista forma parte del acervo de la Biblioteca Jurídica Virtual del Instituto de Investigaciones Jurídicas de la UNAM

Además, admitir la presunción de legitimidad en forma amplia — nos alerta Gordillo_ - "lleva a la consecuencia de proteger la arbitrariedad administrativa, facilitar el exceso y dificultar la efectiva vigencia de los derechos de los individuos". ${ }^{36}$ Por otra parte, abogar por el sostenimiento del solve et repete como una manifestación particular de la ejecutoriedad del acto administrativo implica una desnaturalización del ejercicio de la función jurisdiccional, conculcándose de tal modo el derecho de toda persona a la tutela judicial efectiva. Tal situación se torna, según Spisso, "inconstitucional”, toda vez que "en un Estado de derecho ...resulta inadmisible la obligación de pago sin que exista la posibilidad de que un Tribunal de Justicia evalúe siquiera la procedencia"; 37 de ahí que la ejecución forzosa de la deuda tributaria deba hacerla la administración, por tanto, sin coartar la acción de defensa jurídica del obligado al pago.

Constituye una exigencia en nuestro país la necesidad de un derecho a la tutela judicial efectiva nítida, transparente y sin ondulaciones, lo que sin lugar a dudas es una de las piezas básicas para que cualquier ordenamiento jurídico sea justo y garante de los derechos que protege, si bien a lo largo de los últimos años se ha recorrido un largo trecho, no siempre el camino se manifiesta ausente de astillas y puntos que pulir. Por tanto, de la eliminación de trabas y exclusiones, de la necesaria ampliación de competencias de nuestros órganos jurisdiccionales para enjuiciar la actuación de la administración tributaria, en fin, de la adecuada concepción y articulación de la justicia administrativa y en particular del régimen de lo contenciosoadministrativo, dependerá en gran medida que sea una realidad para nuestros contribuyentes el derecho fundamental de acceso a la justicia.

\section{Impacto del solve et repete en el estatus jurídico del contribuyente}

La doctrina más conspicua ha sostenido, durante los últimos tiempos, la idea visceral que destaca la necesidad de la inmediata aniquilación de la exigencia de la regla solve et repete en materia fiscal, toda vez que se trata de un "fatídico resabio absolutista... en cuyo enunciado se revela la barbaridad jurídica que implica, y su brutal contrariedad con el respeto más elemental

36 Gordillo Agustín, A., Tratado de derecho administrativo. El acto administrativo, Colombia, Fundación de Derecho Administrativo, 1999, pp. 19-28.

37 Spisso Rodolfo, Tutela Judicial efectiva en materia tributaria, Buenos Aires, Depalma, 1996, p. 89. 
Esta revista forma parte del acervo de la Biblioteca Jurídica Virtual del Instituto de Investigaciones Jurídicas de la UNAM www.juridicas.unam.mx https://biblio.juridicas.unam.mx/bjv

https://revistas.juridicas.unam.mx

DOI: http://dx.doi.org/10.22201/ijj.24484881e.2017.37.11456

de los derechos de la persona humana", ${ }^{38}$ al exigir el cumplimiento de la sanción antes que pueda ser reclamada o impugnada.

Tal situación ha motivado un mayoritario rechazo en la doctrina, ${ }^{39}$ que se ha extendido al sector legislativo de varios países, que han tenido el acierto de eliminar esta funesta figura de la normativa tributaria, siendo reputada incluso inconstitucional. ${ }^{40}$

38 Soto Kloss, Eduardo, "El solve et repete. Notas sobre un resabio absolutista en el Estado constitucional de derecho", Revista Ius Publicum, España, núm. 6, 2001, p. 82.

39 Según Villegas, "la regla dista de ser indiscutidamente aceptada por la doctrina", tomando como ejemplo para aseverar esta idea tres pronunciamientos categóricos y de indudable jerarquía científica contra el solve et repete mencionados por Valdés Costa: el emitido en las primeras Jornadas Latinoamericanas de Derecho Procesal, celebradas en Montevideo en 1957, donde se resolvió que "ninguna norma debe establecer el pago previo de las prestaciones reclamadas por la administración como requisito para el ejercicio de recursos administrativos y de la acción de nulidad". El emitido en las segundas Jornadas Latinoamericanas de Derecho Tributario, celebradas en México en 1958, al tratarse su número 2 referido al proceso contencioso-tributario, se adoptó como recomendación que debía "ser eliminado como requisito de procedencia, tanto para la interposición de recursos administrativos, como en el ejercicio de la acción contenciosa, el pago previo de los tributos, sin perjuicio de las garantías que fueran necesarias para los casos de riesgo de incumplimiento del crédito fiscal". El emitido en las Jornadas Luso-HispanoAmericanas de Pamplona, en 1976, en las que se sostuvo en el numeral 16 que "la interposición y decisión de recursos o acciones no debe estar condicionada al pago previo de la obligación impugnada, ni a ningún otro requisito que no tenga relación directa con el objeto del recurso o acción que se deduce". Villegas, Héctor B., Curso de finanzas, derecho financiero y tributario, Buenos Aires, Depalma, 2001, p. 505.

40 En palabras de Martín Oviedo: "El esplendor de esta regla no ha sido duradero y hoy asistimos a una franca recesión de la misma en el Derecho comparado". Los ejemplos que permiten corroborar tal apreciación son diversos. En Italia, la regla fue derogada por declaración de inconstitucionalidad de la Corte Constitucional el 31 de marzo de 1961, tomando como fundamento los resultados marcadamente injustos y dispares que se generaban entre el contribuyente que se encontraba en condiciones de afrontar inmediata y totalmente el tributo y aquel que no contaba con los medios suficientes para satisfacer la obligación, cercenándole a este último, el acceso a la tutela jurisdiccional amparada por la Constitución. Además la aplicación del solve et repete entraba en franca contradicción con el principio de igualdad ante la ley proclamado por la Constitución italiana. De esta forma se hacía especial hincapié en la obligación del Estado de remover los obstáculos de orden económico y social que, al limitar de hecho la libertad y la igualdad de los ciudadanos, impidieran el pleno desarrollo de la personalidad humana y la efectiva participación de todas las personas. Junto a Italia, España fue otro país en el que el solve et repete sufrió la misma tacha de inconstitucionalidad conforme a la sentencia del Tribunal Supremo del 14 de junio de 1973, reafirmada luego por la interpretación brindada a la Constitución reformada de 1978, especialmente en su artículo 24. Martín Oviedo, José M., "La decadencia de la regla solve et repete y la doctrina del Consejo de Estado", Revista de Administración 
Esta revista forma parte del acervo de la Biblioteca Jurídica Virtual del Instituto de Investigaciones Jurídicas de la UNAM www.juridicas.unam.mx https://biblio.juridicas.unam.mx/bjv

https://revistas.juridicas.unam.mx

DOI: http://dx.doi.org/10.22201/ijj.24484881e.2017.37.11456

EL SOLVE ET REPETE EN EL PANORAMA TRIBUTARIO CUBANO...

Sin embargo, tal y como nos alerta Santamaría Pastor, el solve et repete no ha muerto en la legislación, en la doctrina jurisprudencial ni lo que es peor, en las aficiones y reflejos instintivos de una burocracia que se aferra con desesperación a los más deprimentes privilegios. ${ }^{41}$

Lamentablemente queda aún mucho camino por recorrer hasta extinguir los supuestos legales del solve et repete vigentes e impedir que puedan volver a renacer o reproducirse en el futuro; tarea que corresponde, desde luego, al legislador, pero no en menor medida a la doctrina científica y jurisprudencial. Ante esta realidad resulta pertinente ahondar en algunas de las afectaciones que conlleva la exigencia del pago previo para el contribuyente, aludiendo a tales efectos la vulneración que el reconocimiento y aplicación de esta regla genera en algunos derechos.

Pública, España, núm. 43, 1964, p. 149. En Uruguay, la Suprema Corte de Justicia mantiene una jurisprudencia firme en el sentido de que el solve et repete es inconstitucional, por sentencia núm. 75 del 20 de mayo de 1959. En Ecuador, en 1975 entró en vigencia el Código Tributario, y con él se puso fin a la regla del solve et repete. En Venezuela, la entonces Sala Político-Administrativa de la Corte Suprema, en sentencia del 14 de octubre de 1990, declaró, por vía de control difuso de la constitucionalidad, la inconstitucionalidad del solve et repete por violación del derecho a la defensa. De forma similar la aplicación de la regla fue declarada como inconstitucional en Costa Rica por la jurisdicción constitucional. El solve et repete se ha tachado de inconstitucional también porque se considera que entra en contradicción con lo previsto por la Declaración Universal de Derechos Humanos (artículo 11), la Declaración Americana de los Derechos y Deberes del Hombre (artículo XXVI), el Pacto Internacional de Derechos Civiles y Políticos (artículos 14.2 y 26) y la Convención Americana Sobre Derechos Humanos, conocida como Pacto de San José de Costa Rica (artículo 80.). Para consultar estos y otros ejemplos, véase Villegas Héctor B, op. cit., nota 39; Navarrine Susana C., "El principio del solve et repete por el Pacto de San José de Costa Rica", Revista Rentas, Buenos Aires, año X, núm. 1, 1987; Brewer Carías, Allan R., Nuevas tendencias en el contencioso-administrativo en Venezuela, Caracas, Editora Jurídica Venezolana, 1993 y Rojas Franco, Enrique, Derecho administrativo y derecho procesal administrativo, Guayaquil, Editorial Edilex, 2007.

41 Santamaría Pastor, Juan A., "Un paso adelante en la extinción del solve et repete", Revista Española de Derecho Administrativo, Madrid, núm. 2, 1974, p. 311. Además de Cuba, existen otros países en los que aún se mantiene vigente el solve et repete, y en los que se defiende su sostenimiento utilizándose similares argumentos a los defendidos en nuestro país. Como ejemplos podemos citar a Argentina, donde se aplica lo que podría denominarse como un sistema mixto, pues se ha suprimido esta regla a nivel nacional como requisito para interponer los recursos y acciones contra las sentencias del Tribunal Fiscal de la Nación, pero se continúa reconociendo el derecho de la administración de reclamar independientemente el cobro coactivo de la deuda, lo que genera un solve et repete encubierto. En Panamá, con arreglo a las leyes números 135 de 1943 y 33 de 1946, reguladoras del proceso contencioso-administrativo, se exige el depósito previo de la cantidad reclamada. 
Esta revista forma parte del acervo de la Biblioteca Jurídica Virtual del Instituto de Investigaciones Jurídicas de la UNAM www.juridicas.unam.mx https://biblio.juridicas.unam.mx/bjv

https://revistas.juridicas.unam.mx

DOI: http://dx.doi_org/10.22201/ijj.24484881e.2017.37.11456

\section{A. Solve et repete vs. acceso a la justicia. El derecho a la tutela judicial efectiva}

La regla solve et repete, derivada de un viejo privilegium fisci, tal y como aseguran García de Enterría y Fernández, ${ }^{42}$ se configura como presupuesto de admisibilidad de la acción, y obstaculiza, en primer lugar, un derecho de gran magnitud: el derecho de acceso a la justicia, también denominado por la doctrina española como derecho a la tutela judicial efectiva. Así lo han postulado autores como Valdés Costa, quien categóricamente refiere que "el mantenimiento de esta regla hace ilusoria la tutela jurisdiccional", 43 pues como bien ha apuntado Liz: "Exigir el cumplimiento de la obligación que se reclama, como condición previa para poder llegar a que un magistrado determine si su cobro es procedente, obstaculiza el acceso al tribunal imparcial". ${ }^{44}$

En su acepción general el acceso a la justicia, según Casal: "Supone la disponibilidad efectiva de cauces institucionales destinados a la protección de derechos y a la resolución de conflictos de variada índole, de manera oportuna y con base en el ordenamiento jurídico". ${ }^{45}$ Entre estos cauces institucionales encontramos la vía administrativa, la jurisdicción contencioso-administrativa, así como otras instancias encargadas de la resolución alternativa de conflictos.

Si bien en términos amplios el acceso a la justicia consiste en la disponibilidad real de instrumentos de todo tipo, que permitan la posibilidad cierta de acudir ante las instancias facultadas para la protección de derechos y solución de litigios, gran parte de los autores defienden una concepción en sentido estricto, sosteniendo a tales efectos que el acceso a la justicia es un derecho adscrito al derecho a la tutela jurisdiccional o tutela judicial efectiva, tratándose pues de términos equivalentes. ${ }^{46}$

42 García de Enterría, Eduardo y Fernández, Tomás R., Curso de derecho administrativo, t. II, 10. Madrid, Civitas, 2000, p. 635.

43 Valdés Costa, Ramón, op. cit., p. 53.

44 Liz Carlos A., La reforma constitucional de 1994 y la inconstitucionalidad del solve et repete, LL 1996, p. 25.

45 Casal, Jesús M., "Derechos humanos, equidad y acceso a la justicia”, en Colectivo de autores, Derechos humanos, equidad y acceso a la justicia, Venezuela, Instituto Latinoamericano de Investigaciones Sociales, 2005, p. 16.

46 Al respecto, véase Bidart Campos, Germán J., "Panorama de los derechos humanos a fin de siglo", La ciencia del derecho durante el siglo XX, UNAM, Instituto de Inves- 
Esta revista forma parte del acervo de la Biblioteca Jurídica Virtual del Instituto de Investigaciones Jurídicas de la UNAM

El derecho a la tutela judicial efectiva - en palabras de González Pérez al referirse al plano jurídico-administrativo_ _ "es el derecho de toda persona a que se le haga justicia, a que cuando pretenda algo con arreglo a Derecho frente a un ente público, tenga la seguridad de que su petición será atendida por unos órganos independientes y preparados, a través de un proceso con unas garantías mínimas". ${ }^{47}$

Siguiendo el criterio precedente podemos afirmar que la tutela judicial efectiva implica necesariamente la presencia de dos elementos: la negación de trabas para el acceso a los procesos judiciales y la existencia de garantías mínimas que coadyuvan a su efectividad, y que pueden ser resumidas así: un proceso garante de la igualdad de las partes, de la audiencia y la contradicción, el derecho a la defensa y a la asistencia letrada, a la propuesta y práctica de los medios de prueba pertinentes, el derecho a un proceso público y sin dilaciones indebidas, a la obtención de una resolución fundada en derecho sobre las pretensiones deducidas, el derecho a interponer los recursos previstos y a la efectividad de las resoluciones judiciales firmes.

En tal sentido, Dromi ha razonado que: "En tanto el solve et repete traba o imposibilita al contribuyente el recurso ante la justicia lo obliga prácticamente a someter su reclamo al órgano administrativo, que es difícilmente un juzgador imparcial, en tanto es parte interesada"; 48 tratándose pues de "un juicio y un mandato de parte al fungir la Administración Pública al mismo tiempo como juez y sujeto en litigio". ${ }^{49}$

De tal modo, este privilegio procedimental veda el acceso a la justicia, lo que, sin lugar a dudas, es una afectación grave, ya que se trata de un derecho por medio del cual se le da contenido material a la igualdad me-

tigaciones Jurídicas, México, 2011, p. 103; Cifuentes Muñoz, Eduardo, "Acceso a la justicia y debido proceso en Colombia (síntesis de la doctrin a constitucional)", Anuario Iberoamericano de Justicia constitucional, Madrid, 1999, p. 276; Maraniello Patricio, Alejandro, "Las limitaciones económicas al acceso a la justicia", Revista del Instituto de Ciencias Jurídicas de Puebla IUS, México, nueva época, año II, núm. 21, primavera de 2008, p. 106; Colectivo de autores, Acceso a la justicia y derechos humanos en Chile, Costa Rica, Instituto Interamericano de Derechos Humanos, 2010, pp. 18-24; entre otros.

47 González Pérez, Jesús, El derecho a la tutela jurisdiccional, Madrid, Civitas, 2001, p. 33 .

48 Dromi, José R., Institucionales de derecho administrativo, Buenos Aires, Astrea, 1973, p. 146.

49 Couture, Eduardo J., "Algunas proposiciones fundamentales del derecho procesal”, Revista de Jurisprudencia, Derecho y Administración, España, año 54, núm. 2, 1956, p. 30. 
Esta revista forma parte del acervo de la Biblioteca Jurídica Virtual del Instituto de Investigaciones Jurídicas de la UNAM

diante la exigibilidad de otros derechos y la resolución de conflictos entre particulares o entre éstos y el Estado. Por lo mismo, el acceso a la justicia permite dar efectividad a los restantes derechos y determina, por tanto, las posibilidades de defensa de los derechos humanos, constituyendo a la par un requisito para la auténtica garantía jurídica de los mismos.

No debemos olvidar, además, que el derecho a la tutela judicial efectiva es un derecho irrenunciable, no sólo porque, como cualquier derecho humano, es inherente a la condición de la persona como titular de dichos derechos, sino incluso porque es obligación del Estado garantizarlo, evitando en cualquier caso su obstaculización. Por tal motivo, el acceso a la jurisdicción contencioso-administrativa no debe estar supeditada a condiciones o requisitos que le resten efectividad para cumplir con los fines para los que fueron previstos. Si la administración de justicia es el vehículo mediante el cual ha de llevarse a la práctica la obligación estatal de proveer la manera de que las personas puedan dirimir sus conflictos jurídicos para defender sus derechos, la abstención del interesado por razones ajenas a su voluntad que viene de la mano de una regla infraconstitucional como el solve et repete, que lo sitúa en condiciones desfavorables para emprender el litigio, equivale a una denegación de justicia; pues tal y como expresara Casás: "Con la consolidación del Estado de Derecho resulta hoy inimaginable, que frente a dos partes en pugna, una jurídicamente fuerte y poderosa - el Estado - y otra a menudo débil y desvalida en garantías - el contribuyente- - pueda negarse el acceso a los estrados judiciales con la excusa de la falta de pago previo del tributo". 50

De tal forma el sometimiento de la amplia gama de actividades de la administración pública a la revisión judicial ha de ser una regla general, que presida a la jurisdicción contencioso-administrativa, lo cual se ha consolidado en muchos ordenamientos positivos del mundo, incluso por vía constitucional a través de la consagración del derecho a la tutela judicial efectiva. Lo cierto es que en nuestro país es este un acápite que merece especial atención, toda vez que nuestra Constitución - debido a las carencias que, como vimos, posee la regulación constitucional de los derechos en nuestra Ley Primera - no incorpora expresamente entre los principios de funcionamiento del Estado, el control judicial del funcionamiento administrativo ni tampoco reconoce

50 Casas, José O., La tutela jurisdiccional en materia tributaria, III Jornadas Tributarias del Mercosur de 1999, disponible en: http://ipdt.org/uploads/docs/01_SemInt-04_ JOC.pdf (fecha de consulta: 21 de agosto de 2012). 
Esta revista forma parte del acervo de la Biblioteca Jurídica Virtual del Instituto de Investigaciones Jurídicas de la UNAM

expresamente como derecho, la tutela judicial efectiva. ${ }^{51}$ Tampoco aparece previsto de forma expresa en nuestro texto constitucional el derecho de acceso a la justicia, el cual debería incluirse para tener la posibilidad de cuestionar las normativas infraconstitucionales que lo limitan.

No obstante, es la realización de la justicia el fundamento de la actuación de nuestros Tribunales Populares, y así lo ha dejado previsto la Ley Núm. 82 De los Tribunales Populares de 1997, cuando al regular los objetivos a cumplir por los órganos jurisdiccionales en su función de impartir justicia, permite el acceso de todos a los órganos jurisdiccionales a fin de obtener tutela judicial efectiva y en este caso, acceder a una protección real de sus derechos e intereses.

El solve et repete se configura así como verdadera traba al derecho humano de tutela judicial efectiva, que contrasta, según García de Enterría: “Con la facilidad con que cualquiera puede dirigirse al Juez ordinario sin más que cumplir unas reglas elementales y claras". ${ }^{52}$ De igual modo, esta dificultad para alcanzar la revisión judicial del comportamiento administrativo resulta doblemente cuestionable pues, "además de generar situaciones de privación de justicia, esconde en muchas ocasiones una equivocada tendencia a sobreproteger al Estado, situación esta última que frecuentemente, termina operando como un incentivo para que la Administración actúe ilegítimamente"; 53 resultando quebrada de forma paralela la seguridad jurídica. ${ }^{54}$

51 Sin embargo, autores como Borges Frías y Arias Gayoso son del criterio que su fundamento pudiera encontrarse en los artículos 26 y 63, respectivamente, de la Constitución de la República posición esta que no compartimos, pues tales preceptos se refieren a dos instituciones completamente distintas de lo que entraña el contencioso-administrativo: el artículo 26 hace referencia a la responsabilidad de dirigentes y funcionarios, y el 63, por su parte, acoge la figura del derecho de queja y petición; aunque debamos admitir que en algún momento puedan conducir al citado proceso. Borges Frías, Jorge L. y Arias Gayoso, Grethel, "Justicia administrativa en Cuba", disponible en: http://www.avizora.com/publicaciones/derecho/textos/0030_justicia_administrativa_cuba.htm (fecha de consulta: 21 de agosto de 2012). Recordemos que el texto constitucional cubano es mucho anterior a la construcción doctrinal y jurisprudencial española del derecho a la tutela judicial efectiva.

52 García de Enterría, Eduardo, "El principio de la interpretación más favorable al derecho del administrado al enjuiciamiento jurisdiccional de los actos administrativos", Revista de Administración Pública, España, núm. 42, 2014, p. 274.

53 Perrino, Pablo E., "El derecho a la tutela judicial efectiva y el acceso a la jurisdicción contencioso administrativa", Revista de Derecho Público, Buenos Aires, 2003, p. 1.

54 Al decir de Ferrari Yaunner: "La seguridad, para ser alcanzada como fin del Derecho, no debe conformarse con la sola existencia de un sistema normativo que oriente a los hombres qué no hacer, qué hacer y cómo hacerlo. Desde el punto de vista formal esto 
Esta revista forma parte del acervo de la Biblioteca Jurídica Virtual del Instituto de Investigaciones Jurídicas de la UNAM www.juridicas.unam.mx https://biblio.juridicas.unam.mx/bjv

https://revistas.juridicas.unam.mx

DOI: http://dx.doi_org/10.22201/ijj.24484881e.2017.37.11456

Al quedar supeditado el acceso a la instancia judicial al previo pago de la prestación pecuniaria que el acto a impugnar implica, se estaría sentando las bases para que se cree un cauce hacia la inseguridad jurídica al privar a los contribuyentes de la garantía jurisdiccional que representa el libre acceso a órganos imparciales para dirimir sus conflictos con la administración tributaria, quedando restringido el derecho de recurrir sólo ante la propia autoridad administrativa emisora del acto. La seguridad jurídica resulta infringida con la exigencia del pago previo en su doble dimensión: seguridad estrictamente jurídica del y para el individuo en los procesos y la de carácter sociopolítico, que incide cuantitativa y cualitativamente en el incremento de la confianza del individuo en las instituciones jurídicas y políticas. De esta forma, mientras mayor sea la seguridad jurídica que brinde un ordenamiento jurídico determinado, más respeto tendrán los ciudadanos al sistema, lo que se reflejará también en el cumplimiento del derecho.

Además, es la justicia el más alto de los valores del Estado de derecho y el fin último de su existencia, por lo que su realización se impone como un deber esencial de cualquier organización estatal democrática; ${ }^{55}$ de ahí que

pudiera ser suficiente, sin embargo, la práctica social demuestra que si el Derecho no se realiza plenamente y las normas no son respetadas por toda la sociedad, si los ciudadanos no cuentan con verdaderas garantías eficaces para sus derechos, la seguridad se convierte en un discurso político y nadie sentirá su presencia". Ferrari Yaunner, Majela, "La seguridad jurídica y la legalidad: un estudio necesario", en Matilla Correa, Andry (coord.), Panorama de la ciencia del derecho en Cuba. Estudios en homenaje al profesor Julio Fernández Bulté, Universidad de La Habana, Facultad de Derecho, 2009, p. 235.

55 Como bien reconoce Gordillo: "Existen múltiples y fundamentales valores del sistema constitucional... que por su rango normativo son superiores a todo el resto del ordenamiento jurídico y en una adecuada interpretación deben privar sobre las normas inferiores que se aparten de ellos". Gordillo, Agustín A., La administración paralela, Madrid, Civitas, 1982, p. 27. Del mismo modo nos refiere Parejo Alfonso que: "El poder y el ordenamiento estatales no valen, no son tales solo por asumirse y ejercerse el primero conforme a las reglas y los procedimientos constitucionalmente prescritos, por emanar simplemente dicho poder del segundo. Valen porque derivan su validez última de los valores que propugnan y realizan respectivamente... encuentran en dichos valores el parámetro de validez o legitimidad”. Parejo Alfonso, Luciano, Constitución y valores del ordenamiento constitucional y el ordenamiento jurídico, España, Universidad de Alicante, 1997, p. 104. Este criterio, a su vez, es totalmente compartido por Villabella Armengol al concebir a los valores como: "Límites y cauces de la actuación de los sujetos del poder y como elementos calificadores de la fórmula política del régimen, con lo cual matizan puntualmente el techo ideológico de la Constitución, en tanto marco de desarrollo y aplicación de la misma que refleja su alma y espíritu a la luz del cual deben interpretarse sus preceptos, suplirse sus lagunas, y resolverse sus contradicciones, por lo que nos brinda la 
Esta revista forma parte del acervo de la Biblioteca Jurídica Virtual del Instituto de Investigaciones Jurídicas de la UNAM

se deba garantizar que los mecanismos diseñados para la consecución de ese ideal de justicia pasen, en primer lugar, por la posibilidad de los ciudadanos de utilizar los órganos jurisdiccionales para defender sus intereses.

Y es que, precisamente, las garantías jurisdiccionales constituyen actualmente en nuestro país la forma de protección más directa de los derechos humanos. Son los órganos judiciales los que reúnen las condiciones precisas para ejercer tan alta responsabilidad, es a ellos a quienes está constitucionalmente atribuida la función jurisdiccional, esto es, decir el derecho que corresponda a cada uno, la misión de juzgar y hacer ejecutar lo juzgado, son ellos quienes han de tutelar los derechos e intereses legítimos entre los cuales se encuentran los derechos humanos y son en definitiva sus sentencias y resoluciones de obligatorio cumplimiento. Por todo ello los órganos judiciales se convierten en la base, en el escalón principal del sistema de garantías de los derechos humanos. ${ }^{56}$

Sin lugar a dudas escribir hoy sobre el acceso a la justicia o, con mayor propiedad, de la jurisdicción contencioso-administrativa, conlleva sumergirse de lleno en el campo de la protección de los intereses generales que se expresan en el funcionamiento administrativo y en el de los derechos de los administrados frente a la operatividad del aparato administrativo. En este orden es de gran significación lo que, al decir de Matilla Correa, constituye: "Uno de los sempiternos problemas que plantea el ejercicio de la función administrativa y la relación entre la Administración Pública y los administrados en los marcos de realización de esa función pública", ${ }^{57}$ a saber, el tan necesario control judicial del funcionamiento administrativo, sobre todo en materia tributaria. Y es este control tan necesario porque permite comprobar, fiscalizar, inspeccionar, supervisar, en fin, constatar la correspondencia o no entre la actuación de la administración tributaria y lo establecido a tales efectos por el orden jurídico que determina y rige esa actuación; de ahí que se erija en especial vía para respaldar la eficacia jurídica de las relaciones que se derivan del funcionamiento de la adminis-

clave ideológica imprescindible para contextualizar y hacer inteligible un texto constitucional determinado. Villabella Armengol, Carlos M., "La axiología de los derechos humanos en Cuba", en Varios autores, Temas de derecho constitucional cubano, La Habana, Editorial Félix Varela, 2004, p. 295.

56 Cutié Mustelier, Danelia y Méndez López, Josefina, “Tribunales y tutela de los derechos humanos en Cuba, ¿una cuestión pendiente?", Revista del Instituto de Ciencias Jurídicas de Puebla IUS, México, año II, 2008, pp. 224 y 225.

57 Matilla Correa, Andry, op. cit., p. 60. 
Esta revista forma parte del acervo de la Biblioteca Jurídica Virtual del Instituto de Investigaciones Jurídicas de la UNAM www.juridicas.unam.mx https://biblio.juridicas.unam.mx/bjv

https://revistas.juridicas.unam.mx

DOI: http://dx.doi.org/10.22201/ijj.24484881e.2017.37.11456

tración pública y, paralelamente, signifique un medio de protección de los derechos de los contribuyentes.

\section{B. Solve et repete vs. presunción de inocencia}

Como ya se analizaba supra, la tutela judicial efectiva es un derecho cuya funcionabilidad se enmarca en el ámbito procesal, tendente a garantizar un mecanismo eficaz que permita a los contribuyentes restablecer una situación jurídica vulnerada mediante un proceso decidido por un órgano jurisdiccional. Sin embargo, su contenido va más allá del hecho de acceder a los tribunales, pues comporta un conjunto de exigencias y/o garantías procesales que resultan necesarias para que el proceso sea justo, razonable y confiable.

Abarca así este derecho una absoluta prohibición de indefensión, ${ }^{58}$ la imparcialidad del juez ${ }^{59}$ y la celeridad procesal, el derecho a ser oído y juzgado por leyes y tribunales preexistentes, a no ser juzgado por los mismos hechos en virtud de los cuales hubiera sido juzgado anteriormente, al

58 Según Sánchez Gil: "Al derecho de acceso a la justicia es inherente el principio general y abstracto de no indefensión, que determinaría la interpretación y aplicación de las normas procesales de modo que, en máxima medida, las demandas de las personas ante órganos jurisdiccionales sean atendidas y resueltas, pues la falta de atención a ellas podría implicar la firmeza de alguna violación a sus derechos y la imposibilidad de restablecer el orden jurídico. De este principio pueden a su vez derivarse dos subprincipios un poco más concretos: el de inclusión y el llamado pro actione. El primero implica que ningún conflicto de carácter jurídico puede estar sin alguna vía jurisdiccional por la cual se pueda resolver. El segundo deriva en última instancia del principio pro homine que postula una interpretación amplísima de los derechos fundamentales, en aras de su máxima efectividad, lo que para la administración de justicia significa que deberán interpretarse y aplicarse las normas procesales para favorecer la procedencia del derecho de acción y de instancias de impugnación e incidentales que también forman parte del derecho a la tutela jurisdiccional". Sánchez Gil, Rubén, "El derecho de acceso a la justicia y el amparo mexicano", Revista Iberoamericana de Derecho Procesal Constitucional, núm. 4, 2005, p. 250.

59 La imparcialidad del juez es una garantía mínima que debe brindar la jurisdicción y que se exige todo proceso por la misma naturaleza de sus fines. Lo contrario - la parcialidad - significa arbitrariedad manifiesta y falta de idoneidad, con la consiguiente imposibilidad de decir lo que en auténtico sentido corresponde a las partes en derecho. Benalcázar Juan C., "El requisito del pago previo frente a los derechos constitucionales", disponible en: http://www.derechoecuador.com/index.php?option=com_ content $\&$ view $=$ article $\&$ id $=2537:$ el-requisito-del-pago-previo-frente-a-los-derechosconstitucionales \&catid=31:derecho-constitucional (fecha de consulta: 10 de febrero de 2012). 
Esta revista forma parte del acervo de la Biblioteca Jurídica Virtual del Instituto de Investigaciones Jurídicas de la UNAM

restablecimiento o reparación de la situación jurídica lesionada, así como a la presunción de inocencia.

Respecto a este último derecho - presunción de inocencia_ el solve et repete se revela abiertamente en su contra, pues obligar al pago del tributo y de la sanción administrativa como requisito o presupuesto necesario para poder reclamar, equivale a presumir la veracidad del acto sancionatorio, destruyendo así la presunción que supone inocente al inculpado hasta obtener un pronunciamiento definitivo por el órgano jurisdiccional correspondiente. Así, en tanto tales actos administrativos no estén definitivamente firmes, por ausencia de impugnación o por falta de la ratificación resultante del control judicial final de legalidad, no será justo proceder a la ejecución de la deuda tributaria. ${ }^{60}$

En Cuba, el contribuyente que esté en desacuerdo con la resolución dictada por la administración tributaria que resuelve el recurso de reforma, cuenta con sólo quince días hábiles para impugnarla en alzada, teniendo que abonar dentro de este término la cantidad reclamada. Si no lo hace, y no se declara excepcionalmente por la propia administración que conoce el recurso el no cumplimiento de este requerimiento económico haciendo uso de la facultad discrecional otorgada por el Decreto Núm. 308/12, se declara inadmisible el recurso, quedando agotada así la vía administrativa previa, sin poder establecer demanda administrativa en sede judicial. Es posible que el contribuyente no haya podido procurarse los medios económicos durante el plazo para tener derecho a recurrir, pero de cualquier manera la norma con su regulación presume la culpabilidad del ilícito que se le reprocha y, al carecer de oportunidad el contribuyente de acudir a la jurisdicción contencioso-administrativa, pierde el derecho de probar su inocencia.

Evidentemente, mientras el acto administrativo sancionatorio pueda ser objeto de una impugnación y aún no hay decisión final del órgano judicial, existe la duda de si la culpabilidad quedará o no probada, pues estamos constitucionalmente obligados a presumir la inocencia. Esto es así, sin perjuicio de que se consagre la presunción de legitimidad o veracidad del acto administrativo, ya que esta presunción, de rango legal, debe ceder en preferencia frente a la presunción de inocencia.

60 Entienden Calvo Ortega y Checa González que: "La presunción de inocencia choca frontalmente con la ejecutividad inmediata, salvo solicitud de suspensión garantizada a costa del contribuyente, de las sanciones tributarias". Calvo Ortega y Checa González, Derechos y garantías de los contribuyentes, Valladolid, Lex Nova, 1998, p. 513. 
Esta revista forma parte del acervo de la Biblioteca Jurídica Virtual del Instituto de Investigaciones Jurídicas de la UNAM

\section{De tal modo, como bien sostiene Hernández-Mendible:}

Habiéndose producido una decisión administrativa o jurisdiccional que haya establecido la supuesta culpabilidad y la consecuente responsabilidad de una persona, mientras esa decisión no adquiera firmeza por estar pendiente los plazos para la presentación o resolución de los Recursos incoados contra tales decisiones, la presunción de inocencia se mantiene, pues la misma se proyecta a todo lo largo del proceso y únicamente quedará finalmente desvirtuada por la decisión que sea definitivamente firme. ${ }^{61}$

El solve et repete provoca una innegable indefensión en aquellos contribuyentes que no disponen de recursos monetarios u otras garantías para cumplir con el requerimiento económico que esta regla propugna, hecho que a la postre llega a lastimar también el compromiso que todo Estado tiene de asegurar que todos los ciudadanos tengan igualdad de oportunidades, y hagan efectivo su derecho sin sufrir discriminación alguna de por medio.

\section{Solve et repete vs. derecho a la igualdad}

Una primera manifestación de la igualdad con implicaciones jurídicas es precisamente el establecimiento de la igualdad ante la ley, fundada en dos puntos: la asignación de los mismos derechos para todos sin distinción alguna y la exigencia de la generalidad de la ley. ${ }^{62}$ Vinculada esta exigencia al acceso a la justicia, según Birgin y Abramovich, tiene un doble significado:

En un sentido amplio se entiende como garantía de la igualdad de oportunidades para acceder a las instituciones, los órganos o los poderes del Estado que generan, aplican o interpretan las leyes y regulan normativas de especial impacto en el bienestar social y económico. Es decir, igualdad de acceso sin discriminación por razones económicas. ${ }^{63}$

61 Hernández-Mendible, Víctor R., Tutela judicial efectiva y proceso administrativo posibles, disponible en: http://www.tribunalcontenciosooax.gob.mx/revista/revista\%20 TRIBUNA\%201/tutela.pdf (fecha de consulta: 12 de mayo de 2014), pp. 31 y 32.

62 Pérez Portilla, Karla, "Explicitando el principio de igualdad. Notas para su puesta en marcha", en Carbonell Miguel, Derecho constitucional. Memoria del Congreso Internacional de culturas y sistemas jurídicos comparados, México, UNAM, Instituto de Investigaciones Jurídicas, 2004, pp. 727-729.

63 Birgin, Haydée y Abramovich, Víctor, Acceso a la justicia como garantía de igualdad, Buenos Aires, Editorial Biblos, 2005, p. 20. 
Esta revista forma parte del acervo de la Biblioteca Jurídica Virtual del Instituto de Investigaciones Jurídicas de la UNAM

A la igualdad ante la ley como abolición de privilegios se suma la igualdad en la aplicación de la ley — sin excepciones y sin consideraciones personales - y la igualdad en el contenido de la ley, cobrando esta última un sentido particular, al vincular al legislador y manifestarse como una exigencia de razonabilidad normativa cuya eficacia depende también de mecanismos eficientes de control de constitucionalidad y de legalidad de la creación legislativa llamado a realizar por los órganos jurisdiccionales. En tal sentido, nos manifiesta Cassagne que:

Lo esencial de la igualdad radica en la garantía que tienen los administrados para impedir que se estatuyan en las leyes, reglamentos y aun en los actos singulares o concretos de aplicación de normas generales, distinciones arbitrarias o fundadas en propósitos de hostilidad contra personas o grupos de personas o que importen el otorgamiento indebido de privilegios. ${ }^{64}$

No podemos olvidar que, como bien afirma Gordillo, "una norma legislativa o reglamentaria irrazonable, disvaliosa, desviada, persecutoria... es inconstitucional y como tal debe ser anulada o inaplicada en los casos ocurrentes". ${ }^{65}$ De tal modo serán inaplicadas y/o declaradas inconstitucionales aquellas disposiciones de la administración pública que sean lesivas a la igualdad — derecho concebido también como principio constitucional-, y consecuentemente generen un trato discriminatorio.

Evidentemente, al erigirse el pago de la deuda tributaria como requisito para la impugnación de la conducta administrativa, infringe la igualdad, puesto que sólo aquellos contribuyentes que posean los recursos económicos necesarios para afrontar la deuda, podrán cuestionar la juridicidad en sede administrativa o judicial respecto al cobro efectuado; destruyéndose así el inestable equilibrio de las partes litigantes y significando a la par una discriminación en perjuicio de los económicamente débiles. Esta discriminación se manifiesta con base a la posición económica, pues cuando el contribuyente es afectado por una decisión fiscal que establece un tributo que él considera ilegal o por lo menos desmedido, no tiene acceso a ser oído por un juez con las debidas garantías que ello implica, sino posee el dinero suficiente para pagar previamente las sumas que exige la administración.

64 Cassagne Juan C., Derecho administrativo, Buenos Aires, Abeledo-Perrot, t. I, 2006, p. 26.

65 Gordillo Agustín A., op. cit., pp. 23-27. 
Esta revista forma parte del acervo de la Biblioteca Jurídica Virtual del Instituto de Investigaciones Jurídicas de la UNAM

De esta forma, se establece un tratamiento desigual entre el contribuyente que puede pagar inmediata e íntegramente el tributo para poder reclamar y el contribuyente que no cuente con los medios suficientes para hacer el pago previo exigido, quedando así este último en un real estado de indefensión.

Manifiesta en tal sentido Tapia C. que: "La idea central que informa al principio de igualdad en el Derecho Tributario es la exclusión de las relaciones de poder. Ciertamente el Estado no comparece en este proceso como titular de un poder estatal, sino como un acreedor más que busca la tutela de su interés económico". ${ }^{66}$

Por otra parte, el principio de igualdad en el ámbito tributario comporta la exigencia, como afirma Valdés Costa:

De que los sujetos intervinientes deban estar sometidos por igual a la ley y a la jurisdicción, teniendo cada uno de ellos los derechos y obligaciones que establecen las leyes y, ante discrepancias que se produzcan entre ellos sobre el alcance de estos derechos y obligaciones, deberán ser siempre resueltas por jueces idóneos e independientes. La Administración Fiscal, sujeto activo de la relación jurídico-tributaria, actúa como Estado-administrador (no como Estado-legislador o Estado-juez), por lo que en esa actuación se encuentra respecto al contribuyente en un plano de absoluta igualdad; de ahí que cualquier facultad extraordinaria o especial que alegue deba fundarse en un texto constitucional que la establezca. ${ }^{67}$

Insiste este autor además en la necesaria compatibilidad que debe existir entre las facultades que por ley se le otorgue a la administración y los postulados contenidos en las normas constitucionales, pues en el derecho comparado son variados los ejemplos de facultades que violan la Constitución y que, por tanto, son ilegítimas, citando entre ellas al solve et repete.

66 Tapia C., Javier, "Bases para un debido proceso tributario: tres teorías acerca de la relación entre el Estado y los contribuyentes", Revista Chilena de Derecho, Chile, vol. 32, núm. 2, 2005, pp. 332-345.

67 Valdés Costa, Ramón, Principio de igualdad de las partes de la relación juridico-tributaria, disponible en: http://www.ipdt.org/editor/docs/08_Rev21_RVC.pdf (fecha de consulta: 9 de octubre de 2012), p. 109. Entiende este autor que: "El principio de igualdad, referido al Derecho Tributario sustantivo, requiere, como complemento, que la Administración no pueda nunca tener las facultades de decidir definitivamente sus relaciones jurídicas con los contribuyentes. Estos, como todo individuo, tienen derecho a la tutela jurisdiccional y esta no se concibe sin la vigencia de los principios procesales de la igualdad de las partes en el proceso, mediante iguales posibilidades de alegación y defensa ante un juez ajeno a las partes". 
Esta revista forma parte del acervo de la Biblioteca Jurídica Virtual del Instituto de Investigaciones Jurídicas de la UNAM

Y es que si tanto el Estado como el contribuyente se encuentran sometidos a la ley tributaria, como un aspecto particular de aplicación del principio de legalidad vigente en el derecho administrativo, ambos no pueden sino encontrarse en un pie de igualdad frente a la que ha sido concebida como una relación jurídica tributaria. Si el Estado le confiere a la administración tributaria las más amplias facultades de actuación dentro del campo de la imposición, es necesario buscar e imponer límites externos, no inmanentes a la potestad, con el fin de evitar el uso arbitrario, abusivo e ilegítimo de la misma; ocupando, en tal sentido, los derechos humanos un papel transcendental. Por ello, tales facultades y privilegios otorgados a la administración deberán ejercitarse en el marco de la legalidad, sin que en ningún momento limiten o violen el espíritu y contenido de la Constitución.

En este orden resulta oportuno puntualizar que el texto constitucional cubano dedica un capítulo a la igualdad, tanto desde su perspectiva material como jurídica. Fue modificado en 1992, para incorporarle la proscripción de discriminación por motivos religiosos y otros que sean lesivos a la dignidad humana. Así, podemos encontrar en el capítulo sexto diversas formas de manifestación de la igualdad, ya sea en las relaciones familiares, ${ }^{68}$ como en las políticas que establece el Estado, ${ }^{69}$ en cuestiones de género, ${ }^{70}$ en las esferas político-electoral ${ }^{71}$ y laboral, ${ }^{72}$ etcétera.

De esta forma es que a lo largo del texto constitucional, tal y como ha precisado Villabella, se reflejan otras dimensiones de la igualdad, a saber:

Igualdad frente al legislador que impida que este pueda configurar supuestos en la norma de modo tal que otorgue un trato distinto a personas en igualdad de condiciones o un trato igual a quienes no se encuentran legítimamente en una misma posición; e "igualdad en la aplicación de la ley", que obliga a que esta sea aplicada de modo similar a todos aquellos que se encuentran en la misma situación sin que haya posibilidad de distinción por parte del operador jurídico. ${ }^{73}$

La igualdad se nos revela así como un prerrequisito ineludible para el disfrute de los derechos y deberes, un elemento esencial para la realización

\footnotetext{
68 Constitución de la República de Cuba de 1976, artículo 36.

69 Ibidem, artículo 12.

70 Ibidem, artículo 44.

71 Ibidem, artículo 131.

72 Ibidem, artículo 43, apartado tercero.

73 Villabella Armengol, Carlos M., op. cit, p. 322.
} 
Esta revista forma parte del acervo de la Biblioteca Jurídica Virtual del Instituto de Investigaciones Jurídicas de la UNAM

del derecho, la salvaguarda de la legalidad y la seguridad jurídica ciudadana; como un derecho o principio rector que irradia el espíritu y la letra del texto constitucional cubano, y que debe iluminar todos los rincones de nuestro ordenamiento y hacer que el legislador adopte los mecanismos idóneos para garantizarla en cada aspecto de las relaciones jurídicas en la vida social. Asimismo, debe estar presente no sólo en el proceso de creación del derecho, sino también en su aplicación e interpretación, momentos en los que la figura del juez cobra un protagonismo esencial, cuya libertad de actuación estará limitada por la normativa, las circunstancias objetivas en que se produce el hecho y los valores ínsitos en el ordenamiento jurídico.

Íntimamente vinculado al tema de la igualdad se encuentra entonces el denominado control de constitucionalidad y de legalidad de la creación legislativa llamado a realizar por los órganos jurisdiccionales, toda vez que permite garantizarla a través de la suspensión de la aplicación y/o declaración de inconstitucionalidad de aquellas disposiciones de la administración pública que sean lesivas al principio constitucional de igualdad y consecuentemente generen un trato desigual, como es el caso de aquellas que hacen depender el acceso a la justicia al pago previo de lo impugnado, amparándose para ello en el solve et repete, creación legislativa orientada a la defensa del crédito tributario y a la protección de la administración acreedora, carente de validez y legitimidad.

Hoy, a diferencia de la tendencia que progresivamente se ha venido patentizando en el derecho comparado, no contamos con un Tribunal Constitucional que se pronuncie sobre la virtualidad jurídica de la regla solve et repete mediante su contraste con la Constitución y afirme la inconstitucionalidad de la misma. ${ }^{74}$ Tampoco existen dentro del sistema de garantías instituidas, instituciones universales consagradas y de probada eficacia como el amparo constitucional y el Ombudsman.

No resulta posible además impugnar ante nuestros Tribunales Populares actuaciones, actos, resoluciones y disposiciones que causen lesiones a los

74 La Constitución de la República de Cuba regula como atribución de la Asamblea Nacional del Poder Popular, órgano supremo del poder del Estado y único con potestad constituyente y legislativa en la República, la facultad de decidir la constitucionalidad de las leyes y demás disposiciones normativas, atribución esta que resulta cuestionable ante el hecho de que sea el propio Parlamento, hacedor de las leyes, el que controle la constitucionalidad de su decir, erigiéndose así en juez de lo que es parte. Prieto Valdés y Pérez Hernández, "El control de constitucionalidad de las leyes y otros actos. Sus formas en los Estados Unidos y en Cuba", en Prieto Valdés y Pérez Hernández (comps.), Temas de derecho constitucional cubano, La Habana, Editorial Félix Varela, 2004, pp. 369-384. 
Esta revista forma parte del acervo de la Biblioteca Jurídica Virtual del Instituto de Investigaciones Jurídicas de la UNAM www.juridicas.unam.mx https://biblio.juridicas.unam.mx/bjv

https://revistas.juridicas.unam.mx

DOI: http://dx.doi.org/10.22201/ijj.24484881e.2017.37.11456

EL SOLVE ET REPETE EN EL PANORAMA TRIBUTARIO CUBANO...

derechos y libertades reconocidos en la Constitución, y que, por tanto, implica la inconstitucionalidad de aquéllas; ${ }^{75}$ pues al ser eliminada la Sala de Garantías Constitucionales y Sociales, han quedado los tribunales al margen de la trascendental actividad de control constitucional. ${ }^{76}$ Tampoco pueden los órganos jurisdiccionales plantear directamente tal cuestión, pudiendo sólo instar ante el Tribunal Supremo Popular para que en su condición de sujeto legitimado plantee la cuestión a la Asamblea Nacional del Poder Popular, órgano que decidirá en última instancia; quedándoles así vedada la posibilidad de inaplicar la norma que consideren contraria al texto constitucional, atribución esta en manos del Parlamento.

\section{Solve et repete vs. contenido del derecho a la propiedad}

La exigencia de la regla solve et repete en el entorno tributario implica, además, para el contribuyente una afectación en el contenido de su derecho de propiedad, toda vez que al condicionarse la posibilidad de impugnación a la previa liquidación del crédito en discusión — que incluso puede resultar inexistente-, se provoca un perjuicio económico en su patrimonio.

Rosso es uno de los autores que defiende esta idea, argumentando al respecto que:

75 El doctor Fernando Álvarez Tabío en su obra El recurso de inconstitucionalidad, en defensa del valor superior de la Constitución, sostuvo que: "Los preceptos constitucionales representaban la base sobre la que se edificaba toda la armazón jurídica del país integrada por normas diversas, pero todas con un mismo fondo de firmeza y superioridad, lo cual hacía inadmisible establecer categorías entre ellas. La Constitución debía ser interpretada con arreglo a los principios en que descansaba, a las razones en que estaba inspirada y a los fines que habría de cumplir el gobierno que a través de ella se establecía". En la propia obra se reafirma el valor normativo del magno texto cuando destacó que "el supremo órgano de justicia no podía apartarse de sus normas ni tolerar una ley ordinaria que ofendiere los derechos esenciales consagrados en ella". Álvarez Tabío, F., El recurso de inconstitucionalidad, La Habana, Editorial Librería Martí, 1960, pp. 7-10. Otros autores que defienden también el carácter de la Constitución como norma jurídica directamente invocable y aplicable en juicio son: Prieto Valdés, Martha, "Reflexiones en torno al carácter normativo de la Constitución”, en Pérez Hernández, Lissette y Prieto Valdés, Martha (comps.), Temas de derecho constitucional cubano, La Habana, Editorial Félix Varela, 2004; Zamora, Juan C., "La defensa de la Constitución en la legislación cubana", en Matilla Correa, Andry (comp.), Estudios cubanos sobre control de constitucionalidad (1901-2008), México, Argentina, Porrúa, 2009, entre otros.

76 Cutié Mustelier, Danelia y Méndez López, Josefina, La función de los tribunales de salvaguardar la Constitución, en Matilla Correa, Andry (comp.), Estudios cubanos sobre control de constitucionalidad (1901-2008), México, Argentina, Porrúa, 2009, p. 5. 
Esta revista forma parte del acervo de la Biblioteca Jurídica Virtual del Instituto de Investigaciones Jurídicas de la UNAM

Exigir el pago previo de una obligación tributaria establecida por medio de un procedimiento administrativo, y no por un proceso judicial mediante una sentencia, constituye una violación clara a este derecho, por cuanto se está obligando al contribuyente a pagar un tributo - perturbándose así su patrimonio- que todavía no fue juzgado y condenado por un órgano judicial. ${ }^{77}$

En este orden no debemos olvidar que la impugnación del acto por el que se ha determinado administrativamente la existencia de una deuda tributaria, con la consecuente exigencia del previo pago, no suspende la ejecución del mismo, de modo tal que aun cuando se pretenda la revisión del acto se continuará con la recaudación por la vía ejecutiva, valiéndose la administración para ello de la vía de apremio, ${ }^{78}$ manifestación de su poder de autotutela que deja entrever el principio de presunción de legitimidad de los actos administrativos. Este mecanismo, cuya finalidad no es otra que lograr el ingreso coactivo de los débitos del Fisco, puede traer consigo el embargo de bienes del contribuyente incumplidor en la proporción que satisfaga el importe de la deuda tributaria y la multa que corresponda.

Es básicamente la razón que nos permite asegurar que el solve et repete afecta el contenido del derecho a la propiedad del contribuyente, implicando un doble gravamen para el obligado tributario, pues el sujeto se ve obligado a pagar la cantidad adeudada para poder interponer una demanda administrativa en sede judicial, y después deberá correr con el pago de las costas procesales, de la representación letrada y de otros pagos colaterales que puedan sobrevenirse, por lo que la afectación económica es indudable en el ámbito tributario.

77 Rosso, Fernando J., op. cit., p. 76.

78 El procedimiento de apremio en materia fiscal se deriva del carácter ejecutivo de los actos administrativos. Constituye un procedimiento administrativo en el que el ente público titular del crédito tributario procede, sin necesidad de previa sentencia judicial de condena del deudor, a la ejecución expropiatoria de los bienes de este último para transformarlos en una suma de dinero que le permita hacerse cobro del tributo que resulta insatisfecho por falta de prestación del sujeto obligado dentro del periodo voluntario de recaudación. Reyes Rodríguez, Raudel, "Procedimiento en materia fiscal (I). Procedimiento de gestión y cobranza de los tributos", en Varios autores, Apuntes de derecho financiero cubano, La Habana, Editorial Félix Varela, 2007, pp. 197-199. Se encuentra regulado este procedimiento en la Ley Núm. 113/12 y el Decreto Núm. 308/12, artículos 451 y 145 , respectivamente. 
Esta revista forma parte del acervo de la Biblioteca Jurídica Virtual del Instituto de Investigaciones Jurídicas de la UNAM

\section{LA DEFENSA DE LOS DERECHOS HUMANOS. UN IMPERATIVO}

\section{DE TODOS LOS TIEMPOS}

Del análisis realizado en el epígrafe anterior se puede arribar a la siguiente conclusión: el pago previo o solve et repete constituye un privilegio administrativo que dificulta y limita el pleno ejercicio de los derechos humanos.

Evidentemente con la exigencia del pago previo se coloca en una situación de clara indefensión al contribuyente que quiera hacer valer sus derechos e intereses legítimos. Tampoco es proporcionado ni razonable este privilegio, no sólo porque entorpece el acceso a la instancia judicial, sino porque en definitiva impide el acceso a los distintos recursos que prevé el ordenamiento jurídico, a un sistema efectivo de protección cautelar a las pretensiones del particular, así como a la observación de ciertas garantías que aseguren el derecho a un debido proceso y a la obtención de una sentencia eficaz y su correspondiente ejecución.

Opera así el solve et repete en el panorama tributario cubano como verdadero obstáculo al ejercicio de determinados derechos humanos, cuando debía ser lo opuesto, es decir, los derechos humanos deben fungir como límites constitucionales a las potestades, prerrogativas y privilegios de la administración. Y con esto no queremos decir que los derechos sean ilimitados, ${ }^{79}$ sino que cuando se produce una tensión o conflicto - en este caso entre el deber de contribuir con el sostenimiento del gasto público y el pleno ejercicio de derechos humanos universalmente consagrados y amparados - , esta debe ser resuelta mediante una adecuada ponderación, sin que, en modo alguno, la prevalencia de uno vacíe de contenido al otro.

Claro que estamos de acuerdo en que los tributos, como principal fuente de ingresos del Estado que financia el gasto público, requieren de un sistema

79 Tanto el derecho constitucional como el derecho internacional de los derechos humanos consideran legítimas ciertas limitaciones al ejercicio de los derechos asegurados en dos tipos de situaciones diferentes. En situaciones de normalidad institucional, el ejercicio de los derechos puede ser objeto de limitaciones o restricciones en su ejercicio en virtud de razones de orden público. En situaciones de anormalidad institucional, el orden constitucional e internacional de los derechos humanos posibilita el establecimiento de estados de excepción constitucionales, bajo los cuales los gobiernos están autorizados para restringir o suspender temporalmente, por el lapso más breve posible que permita superar la situación de anormalidad, el ejercicio de determinados derechos humanos, no pudiendo nunca afectarse el ejercicio de otros, los que están expresamente contemplados tanto en la Convención Americana de Derechos Humanos como en el Pacto Internacional de Derechos Civiles y Políticos. Nogueira Alcalá, Humberto, op. cit., p. 141. 
Esta revista forma parte del acervo de la Biblioteca Jurídica Virtual del Instituto de Investigaciones Jurídicas de la UNAM

legal que evite retrasos e incumplimientos durante su captación, de ahí que el Estado deberá dotar a la administración tributaria de mecanismos que combatan el incumplimiento o cumplimiento tardío de la obligación tributaria. Sin embargo, se ha de velar porque tales mecanismos no hagan exigua la defensa de los derechos humanos, no debiendo ser ejercidas las potestades y privilegios legalmente conferidos a la administración pública de tal modo que amenacen, perturben o priven a las personas en sus derechos. En otras palabras, no sería admisible actualmente seguir reconociendo esta amplia gama de potestades exorbitantes de la administración del Estado, sin que, por otra parte, se habilitaran mecanismos efectivos de control y garantía de los derechos de los ciudadanos frente al poder. En efecto, tal y como ha aseverado Rodríguez Bereijo:

Las potestades que el ordenamiento confiere a la Administración Tributaria no dan a ésta unas facultades ilimitadas en su actividad inspectora y liquidadora... Se trata en todo caso de potestades tasadas en su contenido y en su finalidad, cuya correcta utilización es susceptible de control jurisdiccional ante los Tribunales de Justicia en garantía de los derechos de los contribuyentes... ${ }^{80}$

Por otra parte, de suprimirse el pago previo no quedaría interrumpido el procedimiento de gestión de los ingresos tributarios - particularmente durante la etapa de recaudación o cobranza-, pues la ONAT cuenta a su favor con otras garantías enfiladas a tutelar la efectividad del crédito debido por el contribuyente deudor. Estaríamos refiriéndonos, por ejemplo, a la vía de apremio, procedimiento administrativo de que dispone la administración tributaria para el cobro forzoso de la deuda tributaria, y en virtud del cual se puede llegar incluso a embargar los derechos y los bienes propiedad del contribuyente, cuando debidamente haya quedado probado el incumplimiento de sus obligaciones tributarias.

Así, una vez que al contribuyente, por medio de resolución fundada dictada por la administración tributaria, se le determine administrativamente la existencia de una deuda tributaria ${ }^{81}$ — ya sea porque haya dejado de satisfacer el tributo en la fecha que resulte exigible o en que habiéndose

80 Rodríguez Bereijo, Álvaro, "El sistema tributario en la Constitución. Los límites del poder tributario en la jurisprudencia del Tribunal Constitucional”, Revista Española de Derecho Constitucional, España, año 12, núm. 36, 1992, p. 66.

81 Artículos 414 de la Ley Núm. 113/12 y 72 del Decreto Núm. 308/12. 
Esta revista forma parte del acervo de la Biblioteca Jurídica Virtual del Instituto de Investigaciones Jurídicas de la UNAM

realizado el pago mediante declaración jurada, proceda la rectificación de la cuantía liquidada - contará con quince días hábiles siguientes a la fecha de notificación de la determinación administrativa para pagar, ${ }^{82}$ término en el que, de no estar conforme el contribuyente, reclamará ante la autoridad emisora del acto haciendo uso de los recursos administrativos que instituye la vigente legislación fiscal. De esta forma se abre el periodo ejecutivo de recaudación, en el que la cuota tributaria inicial se incrementará por la imposición de recargos, ${ }^{83}$ así como por la multa que se le podrá imponer al deudor por la infracción cometida. ${ }^{84}$

Ahora bien, la apertura de este periodo ejecutivo trae consigo que la administración tributaria se haga valer de un procedimiento que permite la ejecución del pago sin que resulte paralizado por la interposición de los recursos de reforma y alzada, ${ }^{85}$ a saber, la vía de apremio, procedimiento que se inicia con la providencia dictada por la autoridad competente de la administración tributaria correspondiente, requiriéndole al deudor que pague el importe de la deuda tributaria en un término de diez hábiles a partir de la fecha en que fuera notificado. ${ }^{86} \mathrm{Si}$ transcurrido este término el deudor no efectúa el pago de lo adeudado a la administración tributaria o no se le admita el acuerdo de aplazamiento solicitado, ${ }^{87}$ se dicta providencia por el director de la ONAT competente disponiendo el embargo de los bienes y derechos de propiedad del apremiado en la proporción que satisface el importe de la deuda tributaria. ${ }^{88}$

Este procedimiento de apremio en materia fiscal se deriva precisamente del carácter ejecutivo de los actos administrativos, de ahí que éstos puedan ser ejecutados por quien corresponda desde que sean exigibles, no teniendo la ONAT necesidad de acudir a los tribunales a obtener una declaratoria de certeza de su derecho, sino que, al contrario, tiene la facultad, por sí mis-

\footnotetext{
82 Artículos 455 de la Ley Núm. 113/12 y 71 del Decreto Núm. 308/12.

83 Artículos 419 al 425 de la Ley Núm. 113/12.

84 Artículos 438 de la Ley Núm. 113/12 y 118 del Decreto Núm. 308/12.

85 Artículos de la Ley Núm. 113/12 y 151 del Decreto Núm. 308/12.

86 Artículos 149 y 150 del Decreto Núm. 308/12.
}

87 "La administración tributaria, cuando así lo considere conveniente, puede aplazar el pago de la obligación o de la deuda tributaria total o parcialmente, con independencia de la forma en que haya sido determinada esta y del momento en que se encuentre el deudor para efectuar su pago, adicionando un interés por aplazamiento". Cfr. Artículos 410 de la Ley Núm. 113/12 y 74 del Decreto Núm. 308/12.

88 Artículos 455 de la Ley Núm. 113/12 y 154 del Decreto Núm. 308/12. 
Esta revista forma parte del acervo de la Biblioteca Jurídica Virtual del Instituto de Investigaciones Jurídicas de la UNAM

ma, para declarar con certeza sus derechos. La administración tributaria no sólo cuenta con esta potestad, sino que además no tiene que acudir a un proceso de ejecución ante los órganos jurisdiccionales, razón por la cual el acto administrativo-tributario deberá por principio ser ejecutado a pesar de la interposición de los recursos contra él.

Lograr el ingreso coactivo de los débitos del Fisco constituye así la finalidad de este procedimiento, valiéndose la ONAT para ello del embargo de los bienes y derechos de propiedad del deudor, y excepcionalmente sobre sus cuentas bancarias. ${ }^{89}$ Por tal motivo, el mantenimiento hoy del solve et repete en nuestra legislación tributaria no responde a la ya tan reiterada justificación de garantizar la recaudación de los ingresos tributarios, constituyendo, eso sí, una reduplicación de los privilegios de ejecutividad y ejecutoriedad de que gozan los actos administrativos, y que trascienden a la esfera fiscal.

Por tanto, si la interposición de recursos contra el acto administrativotributario no suspende su ejecución, ¿qué razón justifica hoy el mantenimiento de este arcaico e injusto instituto que ensombrece nuestro sistema tributario al violentar no sólo el acceso a la justicia, sino además la presunción de inocencia del contribuyente agraviado? Su sólo enunciado devela la contradicción con derechos ampliamente reconocidos y protegidos, instituyéndose en una barrera de tipo económico que entorpece la seguridad jurídica y menoscaba la igualdad. Con base en estos elementos es que abogamos por el destierro total de este privilegio administrativo en nuestra normativa tributaria vigente.

Arribado a este punto no es aventurado plantear que, tal y como ha aseverado Matilla Correa:

De todos los mecanismos procesales existentes en el orden jurídico cubano actual, es el proceso administrativo el que más atrasado se encuentra en términos de desarrollo científico y desenvolvimiento práctico; el que con mayor premura urge reformar para adecuarlo a las nuevas exigencias de los tiempos que corren, liberándolo de viejos dogmas, de anacrónicos prejuicios y de injustificados temores, que lo han tenido confinado a vagar como un fantasma desvalido y disminuido por el espectro jurídico nacional que se ha configurado desde el tercer cuarto del siglo XX hasta la actualidad..$^{90}$

\footnotetext{
89 Artículo 155 del Decreto Núm. 308/12.

90 Matilla Correa, Andry, "Panorama general del derecho administrativo en Cuba", en González-Varas Ibáñez, Santiago (coord.), Derecho administrativo iberoamericano, 2a. ed., Madrid, Instituto Nacional de Administración Pública, 2012, p. 60.
} 
Esta revista forma parte del acervo de la Biblioteca Jurídica Virtual del Instituto de Investigaciones Jurídicas de la UNAM

$\mathrm{Y}$ es que los derechos humanos se erigen en basamento sine qua non para la existencia democrática-institucional de cualquier país, al constituir el factor decisivo para la existencia además del Estado y de su orden jurídico; siendo precisamente a través de ellos que los valores rectores éticos y políticos de la sociedad alcanzan expresión jurídica. Recordemos además que, como atinadamente alega Nogueira Alcalá, "los derechos constituyen el fundamento de la convivencia en paz y justicia en toda sociedad civilizada y en la comunidad internacional. De esta forma, los derechos son el parámetro obligatorio de interpretación y aplicación de todo el derecho; tiene consecuencias para la actuación del Estado en el ámbito del derecho administrativo...". ${ }^{91}$ A la par los derechos constituyen preceptos directamente vinculantes y aplicables; de ahí que deban impregnar todos y cada uno de los sectores del ordenamiento jurídico, no siendo el derecho tributario una excepción.

La eficacia jurídica de los derechos de los contribuyentes dependerá de las posibilidades reales de ejercicio y de la protección con que cuenten dentro del ordenamiento jurídico, de ahí que su aseguramiento constitucional deba ir acompañado de las respectivas garantías, o sea, de un conjunto coherente de instrumentos de defensa que aseguren la observancia efectiva de los derechos asegurados por la Constitución. Es este un propósito que, en el panorama tributario cubano, se satisface fundamentalmente a través de los procedimientos judiciales de control de la administración pública, al ser precisamente los órganos jurisdiccionales los que mayor responsabilidad tienen en lo que concierne a la protección efectiva de los derechos ciudadanos. En efecto, la independencia orgánica de los jueces, unida a su estricto apego a la legalidad, configuran a la jurisdicción contencioso-administrativa, dentro de la justicia administrativa, como el principal instrumento de control y balance de las prerrogativas de los órganos administrativos. En este sentido, la configuración adecuada de las potestades exorbitantes de la administración y su control, para que no devengan en arbitrarias, exigen un sistema eficaz de justicia administrativa, sin la cual no está plenamente asegurado el Estado de derecho.

Lo antes apuntado implica, asimismo, el deber para el legislador de velar porque no se aprueben y promulguen normas jurídicas que instituyan categorías, instituciones, actos, potestades o privilegios que hagan nulo o menoscaben el ejercicio de un derecho humano, quedando vacío su conteni-

91 Nogueira Alcalá, Humberto, op. cit., p. 85. 
Esta revista forma parte del acervo de la Biblioteca Jurídica Virtual del Instituto de Investigaciones Jurídicas de la UNAM

do si no se garantiza que efectivamente pueda ser defendido a través de las garantías que, como indispensables complementos, han de ser consagradas por las normas constitucionales.

Y es que entre Constitución y administración pública existe una relación en la cual la primera determina el ámbito de actuación de la segunda, fijando además los límites en el ejercicio de sus funciones. La administración, a su vez, ha de asegurar los espacios permitidos, aunque como se ha podido advertir, se sobrepase en ocasiones al hacerse valer de privilegios — como es el caso del solve et repete - que abiertamente entra en franca contradicción con derechos que se fundan en la dignidad del ser humano.

En fin, la salvaguarda hoy de los derechos humanos continúa siendo un imperativo de todos los tiempos, toda vez que sus contenidos marcan en el plano jurídico el deber ser, constituyendo una exigencia la instrumentación de garantías que aseguren su consecución plena y efectiva si de defensa del ideal de justicia, de la seguridad jurídica ciudadana y del equilibrio social se trata; debiéndose en tal sentido estimular aún más la invocación de la Constitución y la interpretación conforme a ella, cuando el disfrute de un derecho humano dependa precisamente de la regulación ordinaria.

\section{CONSIDERACIONES FINALES}

La noción de los derechos humanos es fruto del devenir histórico en la búsqueda por acceder a niveles y formas de convivencia comunitaria basadas en el insoslayable principio del respeto a la dignidad del hombre. $\mathrm{Su}$ aseguramiento constituye una obligación y una responsabilidad que todo Estado debe asumir, debiendo en este orden sus diferentes organismos e instituciones asegurar la eficacia práctica de los derechos humanos con todos los medios a su alcance, estableciendo procedimientos normativos y jurisdiccionales que permitan poner fin de forma efectiva a las amenazas, perturbaciones o privaciones al ejercicio de tales derechos.

En función de la dignidad humana y el bien común, cada Estado deberá reconocer y garantizar jurídicamente los derechos humanos _ comenzando por las normas constitucionales_- sin que se precise usar términos como el de "derechos fundamentales" para jerarquizar algunos y dotarles de especial protección respecto a otros, pues todos los derechos son inherentes a todos los seres humanos, sin distinción alguna por razones de nacionalidad, lugar de residencia, sexo, origen nacional o étnico, color, religión, lengua, 
Esta revista forma parte del acervo de la Biblioteca Jurídica Virtual del Instituto de Investigaciones Jurídicas de la UNAM

o cualquier otra condición. Asimismo, deberá cada Estado respetarlos, protegerlos y realizarlos, obligaciones que determinan el compromiso estatal de abstenerse de interferir en el disfrute de los derechos humanos, o de limitarlos; de impedir que sean abusados, así como de adoptar las medidas necesarias para facilitar su disfrute y pleno ejercicio.

De este modo, los derechos humanos coadyuvan a poner un dique a la acción estatal, en el marco de aplicación de la ley, erigiéndose en obligaciones jurídicas, en límites a las potestades, prerrogativas y privilegios de los que goza la administración pública estatal, en fin, en preceptos directamente vinculantes y aplicables que configuran y dan forma al Estado, conforme a los cuales deben ser interpretadas todas las normas que conforman el ordenamiento jurídico, desde la propia Constitución y hasta las resoluciones emitidas por la administración pública.

En Cuba, aún cuando subyacen carencias en lo que se refiere al reconocimiento, calificación y agrupación de los derechos en nuestra carta magna, por mandato constitucional es el culto a la dignidad plena del hombre la ley primera de nuestra República, motivo por el cual no ha de tener cabida en nuestro ordenamiento jurídico, actos y privilegios administrativos que se perfilen como límites a determinados derechos, como es el caso del pago previo o solve et repete, residuo histórico e injustificada regla que, anteponiendo el principio de eficacia recaudatoria, violenta el derecho a la tutela judicial efectiva que conlleva per se, el libre acceso a la administración de justicia, con observancia de un debido proceso y con la certeza de la eficacia de las sentencias. Asimismo, menoscaba la igualdad, el derecho de defensa, el patrimonio del contribuyente y la presunción de inocencia; razones que han motivado el rechazo a esta regla, cuya eliminación progresiva, sin lugar a dudas, coadyuvará a que en nuestro país se evolucione hacia un sistema tributario más justo, que atienda tanto a los intereses estatales como a los de los contribuyentes.

Tal y como pudimos apreciar del análisis de la normativa tributaria actual en nuestro país, la revisión de los actos administrativos en materia tributaria se realiza en primera instancia en vía administrativa, etapa donde es la propia administración la que decide sobre la legalidad de sus actos, provocando un diseño incongruente al ser el propio órgano, juez y parte en la decisión del conflicto, hecho que se recrudece con la exigencia del previo pago. Ante tal situación constituye un reclamo llevar a la práctica una verdadera justiciabilidad de la administración pública, de ahí que sea necesaria la intervención de los jueces en el control de la legalidad de los 
Esta revista forma parte del acervo de la Biblioteca Jurídica Virtual del Instituto de Investigaciones Jurídicas de la UNAM

actos y disposiciones de la administración, a fin de evitar la proliferación de normas jurídicas que establezcan prohibiciones o limitaciones para acceder al ámbito protector del contencioso-administrativo.

Ciertamente, las actividades administrativas son complejas y en grado cada vez más progresivas y no hay actividad del individuo que escape a su intervención, siendo una tendencia universal en los últimos años el fortalecimiento de su poder y el otorgamiento a ésta de atribuciones cada vez más amplias, con el objeto de posibilitarle el cumplimiento más eficaz de los objetivos que la compleja sociedad de nuestros días impone. Ante tal escenario resulta imperiosa, como justa contrapartida para el mantenimiento de la democracia, la potenciación de los mecanismos con que han de contar los gobernados — y en particular los contribuyentes — para la defensa de sus derechos e intereses legítimos, entre ellos, la posibilidad de acudir a los órganos judiciales para enjuiciar la actividad del poder administrador.

$Y$ es que si bien no podemos ni debemos negar el importante papel de los tributos como parte de las finanzas públicas, al constituir la principal fuente de ingresos al presupuesto estatal, así como un importante instrumento de la política económica adoptada por el Estado; la regulación del proceso de captación de estos recursos y la solución de conflictos que se puedan generar en este orden no pueden en medida alguna entorpecer $u$ obstaculizar el derecho que toda persona tiene a hacer valer sus derechos y resolver sus disputas a través de la función jurisdiccional. Y es que además de la tutela judicial efectiva deben prevalecer sobre cualquier privilegio o prerrogativa de la administración, otros derechos universalmente preservados, como resultan ser la igualdad, la presunción de inocencia y el derecho a la defensa; y frente a los cuales el solve et repete se levanta en evidente transgresión.

\section{BIBLIOGRAFÍA}

AgUiAR DE LUQUE, Luis, "Las garantías constitucionales de los derechos fundamentales en la Constitución Española”, Revista de Derecho Político, España, núm. 10, 1981.

AlEXY, Robert, Teoría de los derechos fundamentales, primera reimpresión, Madrid, Centro de Estudios Constitucionales, 1997.

Álvarez TABío, F., El recurso de inconstitucionalidad, La Habana, Editorial Librería Martí, 1960. 
Esta revista forma parte del acervo de la Biblioteca Jurídica Virtual del Instituto de Investigaciones Jurídicas de la UNAM www.juridicas.unam.mx https://biblio.juridicas.unam.mx/bjv https://revistas.juridicas.unam.mx DOI: http://dx.doi_org/10.22201/ijj.24484881e.2017.37.11456

Aragón, Manuel, Constitución, democracia y control, México, UNAM, 2002.

AtienZA, M., Política y derechos humanos, Valencia, Fernando TorresEditor, 1976.

AzCuY, Hugo M., “Análisis de la Constitución cubana”, Revista Papeles de la FIM, Madrid, segunda época, núm. 14, 1998.

BACIGALUPO, Mariano, La discrecionalidad administrativa (estructura normativa, control judicial y limites constitucionales de su atribución), Madrid, Marcial Pons, 1997.

BARREIRO, Rafael, "Algunas reflexiones sobre la constitucionalidad del solve et repete", Tomo Impuestos, Argentina, núm. 49, 1991.

BELlo, H. y JimÉnEZ, D., Tutela judicial efectiva y otras garantías constitucionales procesales, Caracas, Ediciones Paredes, 2004.

BENAlCÁZAR, Juan C., "El requisito del pago previo frente a los derechos constitucionales", disponible en: http://www.derechoecuador.com/ index.php? option $=$ com_content\&view $=$ article $\& i d=2537$ :elrequisitod elpagopreviofrentealos $\bar{d}$ erechosconstitucionales \& catid $=31:$ derecho-c onstitucional.

BIDART CAMPOS, Germán J., "Panorama de los derechos humanos a fin de siglo", La ciencia del derecho durante el siglo XX, México, UNAM, Instituto de Investigaciones Jurídicas, 2011.

, Teoría general de los derechos humanos, México, UNAM, Instituto de Investigaciones Jurídicas, 1989.

BIRgin, Haydée y ABRAMOVICH, Víctor, Acceso a la justicia como garantía de igualdad, Buenos Aires, Editorial Biblos, 2005.

BORGES FrÍAS, Jorge L. y ARIAS GAYOSO, Grethel, "Justicia administrativa en Cuba", disponible en: http://www.avizora.com/publicaciones/ derecho/textos/0030_justicia_administrativa_cuba.htm (fecha de consulta: 21 de agosto de 2012).

BREWER CARÍAS, Allan R., Nuevas tendencias en el contencioso-administrativo en Venezuela, Caracas, Editora Jurídica Venezolana, 1993.

Calvo Ortega, Rafael, Curso de derecho financiero I. Derecho tributario, parte general, Barcelona, Civitas, 2008.

y CHeCA GonzÁlez, Derechos y garantías de los contribuyentes, Valladolid, Editorial Lex Nova, 1998. 
Esta revista forma parte del acervo de la Biblioteca Jurídica Virtual del Instituto de Investigaciones Jurídicas de la UNAM www.juridicas.unam.mx https://biblio.juridicas.unam.mx/bjv

https://revistas.juridicas.unam.mx

DOI: http://dx.doi.org/10.22201/ijj.24484881e.2017.37.11456

CARbonell, Miguel (comp.), El principio constitucional de igualdad. Lecturas de introducción, México, Comisión Nacional de los Derechos Humanos, 2003.

CASAS, José O., La tutela jurisdiccional en materia tributaria, III Jornadas tributarias del Mercosur de 1999, disponible en: http://ipdt.org/ uploads/docs/01_SemInt-04_JOC.pdf.

Cassagne, Juan C., Derecho administrativo, Buenos Aires, Abeledo-Perrot, t. I, 2006.

CASAL, Jesús M., "Derechos humanos, equidad y acceso a la justicia", en Colectivo DE AUTORES, Derechos humanos, equidad y acceso a la justicia, Venezuela, Instituto Latinoamericano de Investigaciones Sociales, 2005.

CAStellanos, Ángel M. et al., "Reflexiones en torno a la protección de los derechos fundamentales en Cuba. Propuesta para su perfeccionamiento", en PÉREZ HeRnández y PRIETO VALDÉS (comps.), Temas de derecho constitucional cubano, La Habana, Editorial Félix Varela, 2004.

Cifuentes MuÑOz, Eduardo, "Acceso a la justicia y debido proceso en Colombia (síntesis de la doctrina constitucional)", Anuario Iberoamericano de Justicia constitucional, Madrid, 1999.

Colectivo de AUtORES, Acceso a la justicia y derechos humanos en Chile, Costa Rica, Instituto Interamericano de Derechos Humanos, 2010.

CONDE Álvarez, Enrique, El régimen político español, Madrid, Tecnos, 1994.

COUTURE, Eduardo J., "Algunas proposiciones fundamentales del derecho procesal”, Revista de Jurisprudencia, Derecho y Administración, España, año 54, núm. 2, 1956.

Cutié Mustelier, Danelia y MÉndez LóPez, Josefina, “Tribunales y tutela de los derechos humanos en Cuba, ¿una cuestión pendiente?", Revista del Instituto de Ciencias Jurídicas de Puebla IUS, México, año II, 2008.

, "La función de los tribunales de salvaguardar la Constitución", en MATilla CORREA, Andry (comp.), Estudios cubanos sobre control de constitucionalidad (1901-2008), Argentina, México, Porrúa, 2009.

_ El sistema de garantías de los derechos humanos en Cuba, tesis doctoral inédita, Cuba, 2001. 
Esta revista forma parte del acervo de la Biblioteca Jurídica Virtual del Instituto de Investigaciones Jurídicas de la UNAM www.juridicas.unam.mx https://biblio.juridicas.unam.mx/bjv https://revistas.juridicas.unam.mx DOI: http://dx.doi.org/10.22201/ijj.24484881e.2017.37.11456

DA SiLVA, Virgílio A., "La interpretación conforme a la Constitución. Entre la trivialidad y la centralización judicial", Revista Mexicana de Derecho Constitucional Cuestiones Constitucionales, México, núm. 12, enero-junio de 2005.

DÁvAlos FERnÁNDEZ, R., Los derechos humanos en la legislación cubana, La Habana, 1989, Colección de Estudios Jurídicos Núm. 7.

DE CASTro, Benito, Los derechos económicos, sociales y culturales. Análisis a la luz de la teoría general de los derechos humanos, España, Universidad de León, 1993.

DiEz-PiCAzO, Luis M., Sistema de derechos fundamentales, 2a. ed., Madrid, Thompson-Civitas, 2005.

Dromi, José R., Institucionales de derecho administrativo, Buenos Aires, Astrea, 1973.

FERRADA BóRQUEZ, Juan C., "Las potestades y privilegios de la administración pública en el régimen administrativo chileno", Revista de Derecho, Chile, vol. XX, núm. 2, 2007.

FERRARI YAUnNER, Majela, "La seguridad jurídica y la legalidad: un estudio necesario", en MATILla CORREA, Andry (coord.), Panorama de la ciencia del derecho en Cuba. Estudios en homenaje al profesor Julio Fernández Bulté, Universidad de La Habana, Facultad de Derecho, 2009.

FIX-ZAMUDIO, Héctor, Los derechos humanos y su protección jurídica y procesal en Latinoamérica, México, UNAM, Instituto de Investigaciones Jurídicas, 1974.

— L L protección procesal de los derechos humanos ante las jurisdicciones nacionales, Madrid, Civitas, 1982.

GARCÍA DE ENTERRÍA, Eduardo, "El principio de la interpretación más favorable al derecho del administrado al enjuiciamiento jurisdiccional de los actos administrativos", Revista de Administración Pública, España, núm. 42, 2014.

GONZÁlez PÉREZ, Jesús, El derecho a la tutela jurisdiccional, Madrid, Civitas, 2001.

Gordillo, Agustín A., La administración paralela, Madrid, Civitas, Ediciones SL, 1982.

, Tratado de derecho administrativo. El acto administrativo, Colombia, Fundación de Derecho Administrativo, 1999. 
Esta revista forma parte del acervo de la Biblioteca Jurídica Virtual del Instituto de Investigaciones Jurídicas de la UNAM www.juridicas.unam.mx https://biblio.juridicas.unam.mx/bjv

https://revistas.juridicas.unam.mx

DOI: http://dx.doi.org/10.22201/ijj.24484881e.2017.37.11456

GozAínI, Alfredo O., El derecho procesal constitucional y los derechos humanos (vínculos y autonomías), México, UNAM, 1995.

HERNÁNDEZ VAlle, Rubén, La tutela de los derechos fundamentales, Costa Rica, 1990.

HERNÁNDEZ-MENDIBLE, Víctor R., Tutela judicial efectiva y proceso administrativo posibles, disponible en: http://www.tribunalcontenciosooax. gob.mx/revista/revista\%20TRIBUNA\%201/tutela.pdf.

HERNÁNDEZ VALLE, Rubén, La tutela de los derechos fundamentales, Costa Rica, 1990.

JINESTA LOBO, Ernesto, "El control jurisdiccional de la administración pública”, Revista Judicial, Costa Rica, núm. 63, año XX, septiembre de 1997.

LIZ, Carlos A., La reforma constitucional de 1994 y la inconstitucionalidad del solve et repete, LL, 1996.

Llovet, Javier, Acceso a la justicia y derechos humanos en Panamá, Costa Rica, Instituto Interamericano de Derechos Humanos, 2009.

MADRID H., Miguel de la, Constitución, Estado de derecho y democracia, México, UNAM, 2004.

MARANIELlO PATRICIO, Alejandro, "Las limitaciones económicas al acceso a la justicia”, Revista del Instituto de Ciencias Juridicas de Puebla IUS, México, nueva época, año II, núm. 21, 2008.

MARTín OviEDO, José M., "La decadencia de la regla solve et repete y la doctrina del Consejo de Estado", Revista de Administración Pública, España, núm. 43, 1964.

MARTín REBOLlO, Luis, "La justicia administrativa ante el texto constitucional", Revista Española de Derecho Administrativo, España, núm. 19, octubre-diciembre de 1978.

MATILla Correa, Andry, "Panorama general del derecho administrativo en Cuba”, en GonZÁlez-VARAS IBÁÑEZ, Santiago (coord.), Derecho administrativo iberoamericano, 2a. ed., Madrid, Instituto Nacional de Administración Pública, 2012.

NAVARRINE, Susana C., "El principio del solve et repete por el pacto de San José de Costa Rica", Revista Rentas, Buenos Aires, año X, núm. 1, 1987.

Nogueira Alcalá, Humberto, Teoría y dogmática de los derechos fundamentales, México, UNAM, Instituto de Investigaciones Jurídicas, 2003. 
Esta revista forma parte del acervo de la Biblioteca Jurídica Virtual del Instituto de Investigaciones Jurídicas de la UNAM www.juridicas.unam.mx https://biblio.juridicas.unam.mx/bjv

https://revistas.juridicas.unam.mx

DOI: http://dx.doi_org/10.22201/ijj.24484881e.2017.37.11456

EL SOLVE ET REPETE EN EL PANORAMA TRIBUTARIO CUBANO...

Ortiz SÁnchez, Mónica y PÉrez PInO, Virginia, Léxico jurídico para estudiantes, Madrid, Tecnos, 2004.

PARejo Alfonso, Luciano, Constitución y valores del ordenamiento constitucional y el ordenamiento jurídico, España, Universidad de Alicante, 1997.

PECES-BARBA, Gregorio, Curso de derechos fundamentales, Universidad Complutense de Madrid, Facultad de Derecho, 1980.

\section{Constitucionales, 1993.}

PÉrez Hernández y Prieto VALdÉs, “Los derechos fundamentales. Algunas consideraciones doctrinales necesarias para su análisis", en PÉREZ HERNÁNDEZ y PRIETO VALDÉS (comps.), Temas de derecho constitucional cubano, La Habana, Editorial Félix Varela, 2004.

PÉREZ LuÑo, Antonio, Los derechos fundamentales, Madrid, Tecnos, 1994.

PÉreZ Portilla, Karla, "Explicitando el principio de igualdad. Notas para su puesta en marcha", en CARBONELl, Miguel, Derecho constitucional. Memoria del Congreso internacional de culturas y sistemas jurídicos comparados, México, UNAM, Instituto de Investigaciones Jurídicas, 2004.

PÉREZ URQUIZA, Yalenni, La solución de los conflictos tributarios en la vía judicial en Cuba, tesis presentada en opción al título académico de doctor en ciencias, inédita, Cuba, 2011.

PERrINO, Pablo E., "El derecho a la tutela judicial efectiva y el acceso a la jurisdicción contencioso administrativa", Revista de Derecho Público, Buenos Aires, 2003.

PRIETO VALDÉS, Martha, "La defensa de los derechos: una necesidad en cualquier momento", en Matilla CorreA, Andry y Álvarez-TABío, Ana M. (coords.), El derecho público en Cuba a comienzos del siglo XXI. Homenaje al doctor Fernando Álvarez Tabio, La Habana, Editorial UH, 2011.

QuiRoga CuBILla, Derechos y garantías constitucionales en el proceso, Ediciones Librería del profesional, 1987.

REYES Rodríguez, Raudel, "Procedimiento en materia fiscal (I). Procedimiento de gestión y cobranza de los tributos", en VARIOS AUTORES, Apuntes de derecho financiero cubano, La Habana, Editorial Félix Varela, 2007. 
Esta revista forma parte del acervo de la Biblioteca Jurídica Virtual del Instituto de Investigaciones Jurídicas de la UNAM www.juridicas.unam.mx https://biblio.juridicas.unam.mx/bjv https://revistas.juridicas.unam.mx

DOI: http://dx.doi.org/10.22201/iij.24484881e.2017.37.11456

Rodríguez Arana, Jaime y SARmiento Acosta, Manuel, "El contencioso-administrativo como elemento garantizador de los derechos humanos", Actualidad Administrativa, Revista Semanal Técnico-Jurídica de Derecho Administrativo, España, 1993.

RoBERT, Alexy, Teoría de los derechos fundamentales, CEC, 1993.

RodríGUEz BEREIJO, Álvaro, "El sistema tributario en la Constitución. Los límites del poder tributario en la jurisprudencia del Tribunal Constitucional", Revista Española de Derecho Constitucional, España, año 12, núm. 36, 1992.

RoJAS FRANCO, Enrique, Derecho administrativo y derecho procesal administrativo, Guayaquil, Editorial Edilex, 2007.

Rolla, Giancarlo, Derechos fundamentales, Estado democrático y justicia constitucional, México, UNAM, Instituto de Investigaciones Jurídicas, 2002.

Rosso, Fernando J., El solve et repete en el derecho tributario argentino: problemas y soluciones posibles, disponible en: http://imgbiblio.vaneduc.edu.ar/fulltext/files/TC051174.pdf.

SÁNCHEZ GIL, Rubén, "El derecho de acceso a la justicia y el amparo mexicano", Revista Iberoamericana de Derecho Procesal Constitucional, núm. 4, 2005.

SÁNCHEZ MORÓn, Miguel, "El derecho a la tutela judicial efectiva como límite a la ejecutividad de los actos administrativos", Revista Española de Derecho Administrativo, España, núm. 35, 1982.

SANTAMARÍA PASTOR, Juan A., "Un paso adelante en la extinción del solve et repete", Revista Española de Derecho Administrativo, Madrid, núm. 2, 1974.

SILVA SÁNCHEZ, Manuel, El proceso contencioso administrativo en materia tributaria, Madrid, Marcial Pons, 1992.

SimÓN OTERO, Liana, La protección del contribuyente en Cuba: una visión desde el derecho constitucional tributario, tesis presentada en opción al título académico de Máster en derecho constitucional y administrativo (inédita), Universidad de La Habana, 2011.

Soto KLOSS, Eduardo, "El solve et repete. Notas sobre un resabio absolutista en el Estado constitucional de derecho", Revista Ius Publicum, España, núm. 6, 2001. 
Esta revista forma parte del acervo de la Biblioteca Jurídica Virtual del Instituto de Investigaciones Jurídicas de la UNAM www.juridicas.unam.mx https://biblio.juridicas.unam.mx/bjv https://revistas.juridicas.unam.mx DOI: http://dx.doi.org/10.22201/ijj.24484881e.2017.37.11456

SPISSO, Rodolfo, Tutela Judicial efectiva en materia tributaria, Buenos Aires, Depalma, 1996.

TAPIA C., Javier, "Bases para un debido proceso tributario: tres teorías acerca de la relación entre el Estado y los contribuyentes", Revista Chilena de Derecho, Chile, vol. 32, núm. 2, 2005.

Truyol y SERra, Antonio, Los derechos humanos, Madrid, Civitas, 1968.

VAldÉS CostA, Ramón, "El contencioso tributario. Comunicación presentada a las Segundas Jornadas Latinoamericanas de Derecho Tributario, efectuadas en México, en octubre de 1958", disponible en: http:// www.google.com.cu/search? $q=$ Ram $\% C 3 \% B 3 n+$ Vald $\% C 3 \% A 9 s+C o s$ ta $\% 3 A+E l+$ contencioso + administrativ\&ie $=u t f 8 \& o e=u t f 8 \& a q=t \& r l s$ =org.mozilla:esES:officia\&client=firefox-a.

VAldés CostA, Ramón, Principio de igualdad de las partes de la relación jurídico-tributaria, disponible en: http://www.ipdt.org/editor/ docs/08_Rev21_RVC.pdf (fecha de consulta: 9 de octubre de 2012).

VÁZQUez Alfaro, José L., El control de la administración pública en México, México, UNAM, 1996.

VEGA GÓMEz, Juan y CoRzo SosA, Edgar, “Tribunales y justicia constitucional", Memoria del VII Congreso Iberoamericano de Derecho Constitucional, México, UNAM, Instituto de Investigaciones Jurídicas, 2002.

Villabella Armengol, Carlos M., "La axiología de los derechos humanos en Cuba", en VARIOS AUTORES, Temas de derecho constitucional cubano, La Habana, Editorial Félix Varela, 2004.

, "Los derechos humanos. Consideraciones teóricas de su legitimación en la Constitución Cubana", en VARIOS AUTORES, Temas de derecho constitucional cubano, La Habana, Editorial Félix Varela, 2004.

VILlEGAS, Héctor B., Curso de finanzas, derecho financiero y tributario, Buenos Aires, Depalma, 2001.

ZAMORA, Juan C., "La defensa de la Constitución en la legislación cubana", en MATIlla CORREA, Andry (comp.), Estudios cubanos sobre control de constitucionalidad (1901-2008), Argentina, México, Porrúa, 2009.

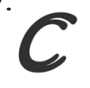

Fecha de recepción: 14 de enero de 2016.

Fecha de dictamen: 30 de marzo de 2017. 